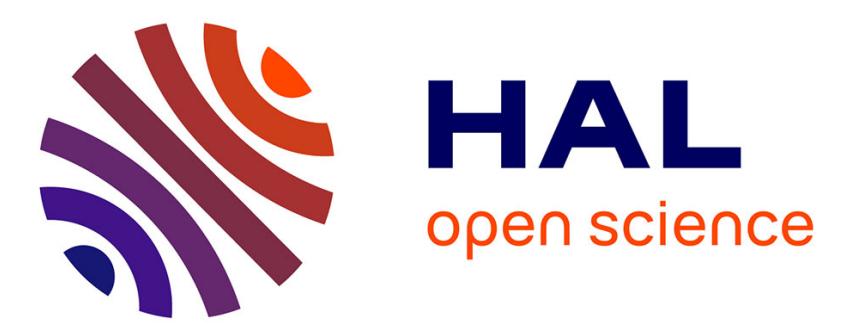

\title{
Testing, Model Simulations of the Thermocline Depth Variability in the Tropical Atlantic from 1982 through 1984
}

Pascale Braconnot, Claude Frankignoul

\section{- To cite this version:}

Pascale Braconnot, Claude Frankignoul. Testing, Model Simulations of the Thermocline Depth Variability in the Tropical Atlantic from 1982 through 1984. Journal of Physical Oceanography, 1993, 23 (4), pp.626-647. 10.1175/1520-0485(1993)0232.0.CO;2 . hal-00154015

\section{HAL Id: hal-00154015 https://hal.science/hal-00154015}

Submitted on 3 Feb 2021

HAL is a multi-disciplinary open access archive for the deposit and dissemination of scientific research documents, whether they are published or not. The documents may come from teaching and research institutions in France or abroad, or from public or private research centers.
L'archive ouverte pluridisciplinaire HAL, est destinée au dépôt et à la diffusion de documents scientifiques de niveau recherche, publiés ou non, émanant des établissements d'enseignement et de recherche français ou étrangers, des laboratoires publics ou privés. 


\title{
Testing Model Simulations of the Thermocline Depth Variability in the Tropical Atlantic from 1982 through 1984
}

\author{
Pascale Braconnot and Claude Frankignoul \\ Laboratoire d'Océanographie Dynamique et de Climatologie, Université Pierre et Marie Curie, Paris, France
}

(Manuscript received 11 December 1991, in final form 27 May 1992)

$c$

ABSTRACT

The multivariate model testing procedure of Frankignoul et al. has been extended to the general time-series case, thus allowing to test ocean model ability at simulating the interannual variability. The method aims at distinguishing between model inadequacies and data uncertainties; model performances are assessed from a misfit evaluated in a space of strongly reduced dimension with basis vectors issued from a double application of common principal component analysis. The testing procedure has been used to investigate the ability of Cane's linear multimode model at simulating the evolution of the $20^{\circ} \mathrm{C}$ isotherm depth in the equatorial Atlantic during the 1982-1984 FOCAL/SEQUAL experiment. Using Monte Carlo techniques and five different drag laws, 25 equally plausible wind-stress fields were constructed to represent the wind-stress uncertainties consistently with the sample means and variances of the original ship measurements. Even during this well-sampled period, the forcing uncertainties were substantial, with corresponding model response uncertainties as large as the interannual variability; the largest source of uncertainty is the drag coefficient indeterminacy, except in poorly sampled areas where sampling and measurement errors become comparable.

Although the linear multimode model successfully simulates many features of the thermocline depth variability, there are some discrepancies with the observations, as in the Gulf of Guinea where the model poorly reproduces the eastward progression of the equatorial upwelling during summer. The multivariate analysis shows that the model-reality differences, too large to be explained by forcing and initial conditions uncertainties, are mostly due to model deficiencies. As the FOCAL/SEQUAL data provide a very stringent test of model performances, they are particularly useful for model tuning and intercomparison. The superiority of the three-mode version of the linear model over the two-mode one is thus more clearly established than in a previous comparison with the mean seasonal variations of the surface dynamic topography, and the LODYC general circulation model is shown to represent the 1982-84 changes in thermocline depth significantly better than the linear model.

\section{Introduction}

Although model simulations of the primarily winddriven circulation of the tropical oceans have become increasingly accurate, they generally show major discrepancies when compared with the observations. Some discrepancies are due to the uncertainties in the surface wind stress, which is particularly unreliable in the tropics where marine observations are sparse, and the synoptic global analysis must still be improved. Others can be attributed to the sparseness and the noise of the oceanic observations. Yet data uncertainties are unlikely to explain all the model-observation differences, and substantial errors arise from model deficiencies and unsatisfactory parameterizations. Without proper methodology, however, model and data errors

Corresponding author address: Prof. Claude Frankignoul, Laboratoire d'Oceanographie Dynamique et de Climatologie, Universite de Paris VI, LODYC, 4 Place Jussieu, Tour 14, 2e étage, 75232 Paris Cedex OS, France. are difficult to distinguish, and the data uncertainties are a prime obstacle to model tuning and improvement.

This is illustrated by recent tropical Pacific simulations where the effects of observational uncertainties and poorly known atmospheric forcing were investigated. Using a linear model, McPhaden et al. (1988) computed the mean seasonal response of sea level and dynamic height to three different wind stress climatologies and compared the results to expendable bathythermograph (XBT) and tide gauge data. Visual comparisons and coherence analysis suggested that forcing uncertainties and limitations in the model physics both contributed to the model-observation discrepancies. Using the same wind stress fields, Landsteiner et al. (1990) compared Sverdrup and geostrophic transports along ship lines and concluded that wind stress uncertainties were responsible for the major differences between simulations and observations; however, we believe that their results are also indicative of systematic model errors. Five different wind stress products were used by Harrison et al. (1989) to hind- 
cast the upper-ocean conditions during the 1982-83 El Niño event with a general circulation model (GCM). The hindcasts differed substantially, but generally bracketed the observations inside the equatorial waveguide, so that it was concluded that the model physics was plausible and that improved wind stress and heat flux data were needed to adequately assess the model performance. This was also emphasized in the sensitivity studies and data assimilation experiments of Leetmaa and Ji (1989).

As the density of ship measurements is relatively large over most of the tropical Atlantic, the wind stress field is better documented and model deficiencies should be easier to detect. Yet traditional model validation studies have remained somewhat inconclusive, even when using the large upper-ocean dataset collected during the FOCAL/SEQUAL experiment (19821984) (Weisberg 1984; Katz 1987). Comparing estimates from inverted echo sounder data of the North Equatorial Countercurrent (NECC) to a simple linear prediction, Katz (1977) suggested that the agreement was as good as could be expected from the forcing uncertainties. Forcing Cane's (1984) linear model with two different wind stress products, Du Penhoat and Gouriou (1987) found important differences in the dynamic height response, but could not establish whether they sufficed to explain the discrepancies with the FOCAL/SEQUAL observations. Reverdin et al. (1991) showed that the GCM of the Laboratoire d'Océanographie Dynamique et de Climatologie (LODYC) could reproduce most of the large-scale, lowfrequency features of a variety of FOCAL/SEQUAL observations and analyzed fields (dynamic height, $20^{\circ} \mathrm{C}$ isotherm depth, surface currents); however, areas of systematic differences could also be found. Although the observational uncertainties were thoroughly assessed, it could not be established whether these differences were due to model deficiencies or to poor initial conditions and inaccurate forcing. This also holds for the simulations of Carton and Hackert (1989).

The uncertainties in the atmospheric forcing and the initial conditions induce uncertainties in model response that have large correlation scales. Hence, the usual point-by-point (univariate) comparisons with the observations, which also often have correlated errors, are difficult to interpret, and a multivariate viewpoint is both more accurate and more powerful. In the context of the mean seasonal variability of the tropical Atlantic, Frankignoul et al. (1989) developed a multivariate approach to model testing where the main space and time structures of the model-observation differences are compared to those of the errors due to the data uncertainties. The linear model of Cane (1984) was shown to be somewhat inconsistent with the observed seasonal variations in surface currents (Frankignoul et al. 1989) and surface dynamic topography (Duchêne and Frankignoul 1991), even when taking into account many sources of data uncertainties, in- cluding observational and sampling errors, interannual variability, and indeterminacy in the wind-stress bulk formulation. Similar results were found for a two-layer nonlinear model and for the LODYC GCM, although the latter performed significantly better than the simplified models (Duchêne and Frankignoul 1990; Frankignoul 1991).

The multivariate model testing procedure, which was developed for the case of the mean seasonal cycle, is extended here to the comparison between simulations and observations of the interannual variability. The general time series case requires using a different approach to represent the forcing uncertainties. Indeed, in the seasonal case they could be simply represented by considering the model response to a multiyear forcing dataset; as each simulated year was an approximately independent realization of the seasonal cycle, interannual variability and random errors were automatically represented in the error covariance matrix of the mean model response. In the time series case, several "plausible" forcing fields that are representative of the forcing indeterminacy during a specific period are needed, and the uncertainties in the initial conditions must be simulated. The wind stress uncertainties could be represented by using several wind stress products as in Harrison et al. (1989), even though it implies using products of unequal quality. Alternatively, as done here, one could go back to the original ship measurements and use a Monte Carlo approach to simulate the forcing uncertainties, consistently with the density and dispersion of the observations. In the time series case, the data compression needed for the multivariate test (Frankignoul et al. 1989) must also be refined, as the time series may be very long. This is done here by performing a double data compression based on principal component analysis.

The "generalized" model testing procedure is presented in a specific context: the evaluation of model ability at reproducing the $20^{\circ} \mathrm{C}$ isotherm depth changes in the tropical Atlantic during the three-year FOCAL/ SEQUAL period. Except in the Gulf of Guinea, where it may get very close to the surface, the $20^{\circ} \mathrm{C}$ isotherm depth is representative of the thermocline depth; its changes are indicative of vertical motions and related to equatorial upwelling, and they control in part the upper-layer heat content. Also, the thermocline depth changes are primarily wind driven and little influenced by the surface heat exchanges, so that the uncertainties of the latter need not be considered. The simple, but computationally efficient, linear multimode model of Cane (1984) is again considered in this first application, as the methodological developments required numerous simulations. Preliminary results, however, are also given for the more sophisticated LODYC GCM.

The plan of the paper is as follows. The estimation of the wind stress field during 1981-84 and the simulation of its uncertainties using a Monte Carlo approach are described in section 2 . The thermocline depth evo- 


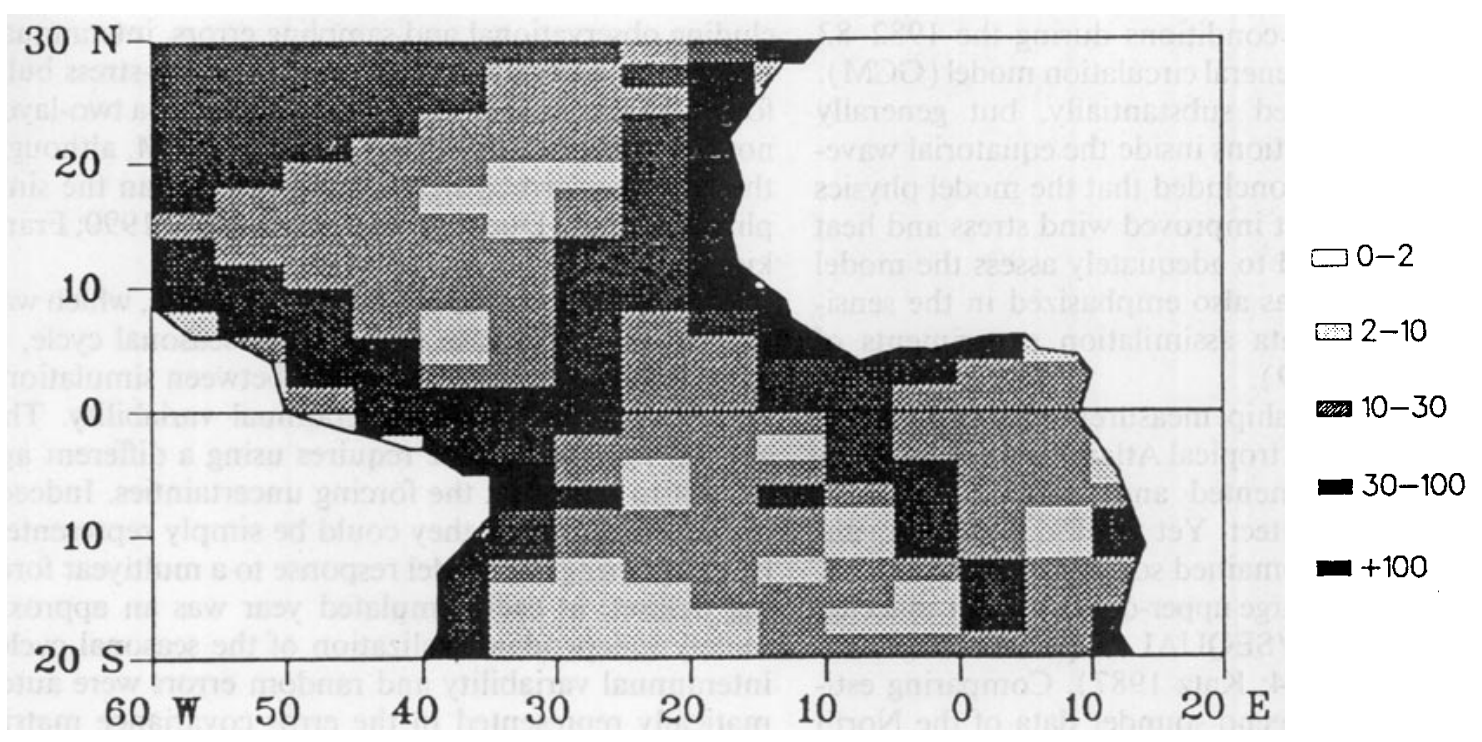

FIG. 1. Mean number of pseudostress observations per month from 1981 through 1984.

lution, as described by the analyzed fields of Reverdin et al. (1991) and simulated with the linear model, is summarized in section 3 . The testing procedure is given in section 4, and the GCM discussed in section 5.

\section{The uncertainties of the tropical Atlantic wind stress during 1981-84}

\section{a. Estimating the wind stress from ship reports}

As the operational products remain unsatisfactory in the tropical band and the density of ship reports is not too small over most of the tropical Atlantic, the wind stress is best estimated from ship data. This involves several steps. Individual wind measurements are first edited and used to calculate the pseudostress (the surface wind vector $\mathbf{u}^{a}$ times its magnitude); the data are then binned into a regular grid, and first and second moments calculated for each month. Here we use the $2^{\circ} \times 5^{\circ}$ pseudostress dataset of Servain et al. (1985), which was available during $1981-84$ between $20^{\circ} \mathrm{S}$ and $30^{\circ} \mathrm{N}$. For the FOCAL/SEQUAL (F/S) years (198284 ), however, this dataset is replaced between $20^{\circ} \mathrm{S}$ and $20^{\circ} \mathrm{N}$ by that of Reverdin et al. (1991), which has three times more data than the original set. Except along the main commercial ship lines where the sampling is sufficient for an accurate estimation of the monthly means (this requires at least 20 values, according to Luther and Harrisson 1984), the averaged number of samples per month remains small (Fig. 1), and the pseudostress field is noisy.

The second step involves the interpolation of data gaps and the smoothing of the fields. Rather than using the successive correction method of Servain et al. (1985), we apply the filtering method of Duchêne (1989), which was shown to provide more accurate results in this region. The data gaps (only $2 \%$ ) are first linearly interpolated, and a principal component analysis is performed; smoothed fields are reconstructed by keeping only the principal components and associated empirical orthogonal functions (EOFs) that can be distinguished from white noise. For better resolution, the EOFs are calculated over the longer $1964-84$ period, using the product of Servain et al. (1985) for the earlier years. As in Duchêne (1989), the first 25 EOFs are retained.

The surface wind stress $\tau$ is then calculated using the bulk formulation

$$
\tau=\rho^{a} C_{D}\left|\mathbf{u}^{a}\right| \mathbf{u}^{a},
$$

where $\rho^{a}$ is the air density and $C_{D}$ the drag coefficient, which depends on wind speed and atmospheric boundary-layer stability. The stability dependence is estimated from the air-sea temperature difference. Blanc (1987) has warned that the stability estimated from individual ship reports is so noisy that it may actually degrade the accuracy of wind stress estimates. Thus, we use only monthly means to calculate the stability correction. For 1982-84, the calculation is done by prescribing a relative humidity of $80 \%$ and using monthly air-sea temperature differences computed from ship reports (courtesy of $G$. Reverdin). As these data are sparse and very noisy, the monthly means are smoothed by first filtering the mean seasonal cycle over the 3 years using EOF truncation and then applying a $1 / 4-1 / 2-1 / 4$ smoothing to the monthly anomalies. Climatology is used for 1981 .

\section{b. Drag coefficient uncertainties}

Several drag laws with somewhat different dependence in wind speed and atmospheric stability are 


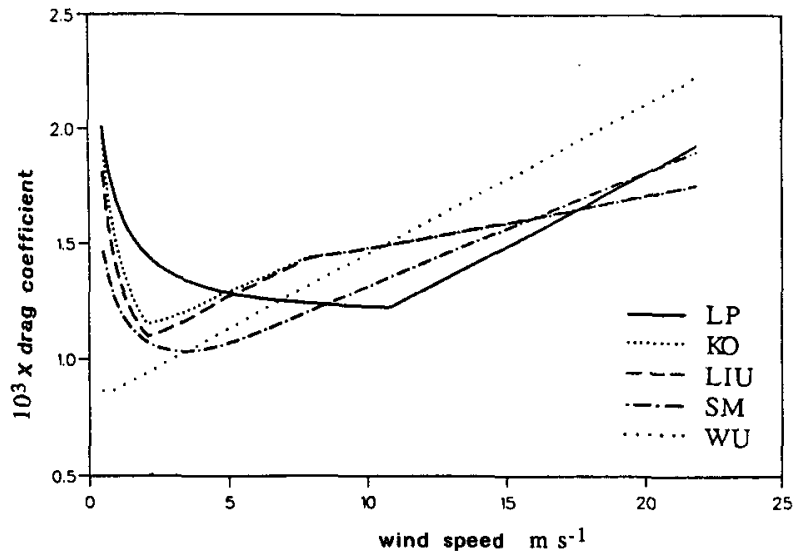

FIG. 2. The five selected drag coefficients as a function of wind speed for an air-sea temperature difference of $0.5^{\circ} \mathrm{C}$ (see text). Values are in $10^{-3}$.

available in the literature, but none of them seems universally accepted. Following Blanc's (1985) estimation of the indeterminacy in the drag value, Frankignoul et al. (1989) allowed a 20\% random indeterminacy around the particular drag formulation chosen for the simulations. This provides the correct order of magnitude, but neglects geographical and seasonal variations. To be more realistic, here we employ five commonly used and equally acceptable bulk parameterizations to construct plausible wind stress fields, namely those of Large and Pond (1981), Kondo (1975), Liu et al. (1979), Smith (1988), and Wu (1985) (referred to as LP, KO, LIU, SM, and WU, respectively). Figure 2 compares the five drag coefficients as a function of wind speed for an air-sea temperature difference of $-0.5^{\circ} \mathrm{C}$. The largest dispersion is found at the low wind speeds that are often found in equatorial areas. Note that Kondo and Liu's laws behave somewhat similarly in this weakly stratified case, as they are similar in neutral conditions.

The drag uncertainty, quantified by the mean square wind stress differences between all pairs of drag laws during 1982-84, is substantial, with an rms schemeto-scheme variation ranging from 4 to $11\left(\times 10^{-3}\right.$ $\mathrm{N} \mathrm{m}^{-2}$ ) (Fig. 3a). It is as large as 30\% of the seasonal changes of the wind stress (Fig. $4 \mathrm{a}$ ), and up to $80 \%$ of its interannual variability (Fig. 4b). The largest uncertainties are found in regions of strong trade winds, between $5^{\circ} \mathrm{N}$ and $10^{\circ} \mathrm{N}$ during (Northern Hemisphere) winter and around $10^{\circ} \mathrm{S}$ during summer.

As most tropical wind stress products neglect the stability dependence of the bulk coefficient, we have also investigated the influence of the latter by comparing wind stresses estimated with and without stability correction. As illustrated in Fig. $3 c$ for the LP formulation, rms differences with the neutral cases are typically 2 to $3\left(\times 10^{-3} \mathrm{~N} \mathrm{~m}^{-2}\right)$, primarily reflecting the seasonal changes in stability. Although neglecting the stability dependence causes errors that are smaller than the drag uncertainty, the former errors can reach up to $50 \%$ of the latter in upwelling regions. Thus, stability dependence should be included in tropical wind stress calculations.

\section{c. Sampling uncertainties}

Indeterminacy in wind stress estimates also arises from measurement errors, interpolation, and aliasing. The ship reports are based on Beaufort estimations or anemometer readings. The Beaufort scale has an intrinsic uncertainty of about $2 \mathrm{~m} \mathrm{~s}^{-1}$ (Harrisson 1984), and the subjective judgment of individual observers can introduce supplementary errors. Anemometer readings are more objective, but the anemometer can
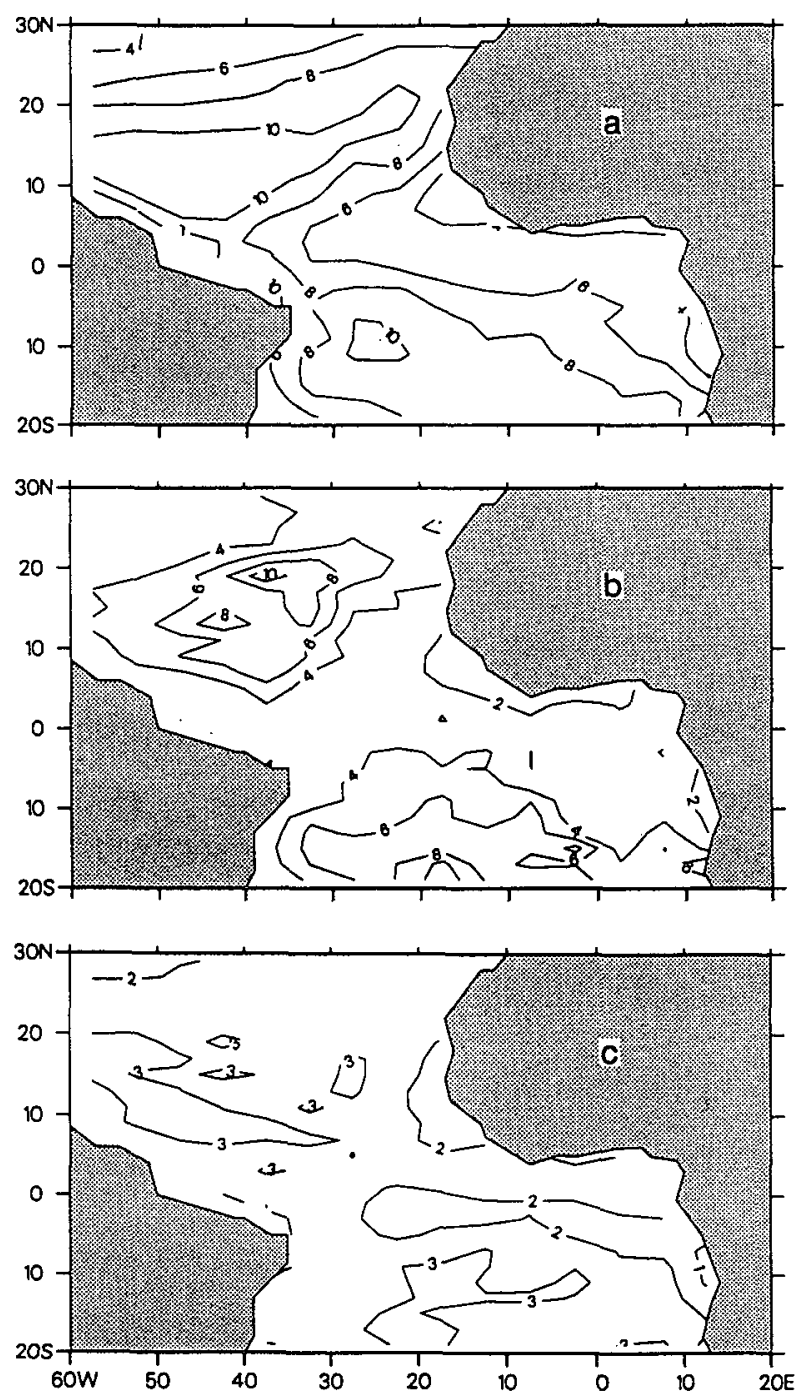

FIG. 3. Wind-stress uncertainties (rms) caused by (a) the drag coefficient indeterminacy and (b) the sampling errors. (c) Rms error due to the neglect of the stability correction in the LP bulk formula. Isolines are in $10^{-3} \mathrm{~N} \mathrm{~m}^{-2}$. 

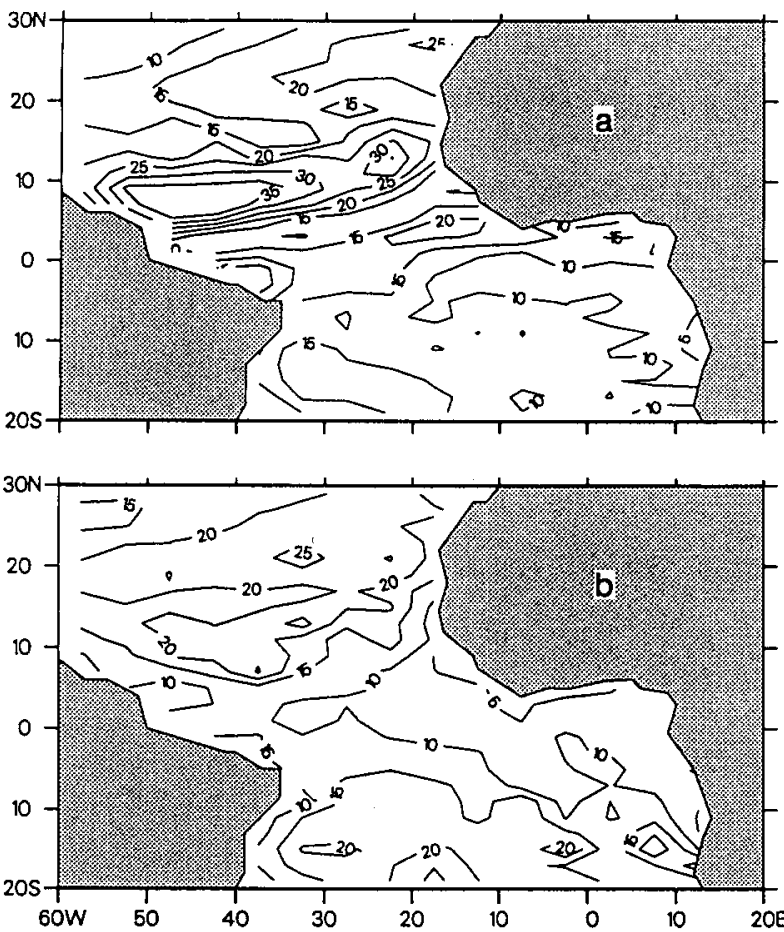

FIG. 4. (a) Seasonal and (b) interannual variability (rms) of the wind stress calculated using the LP drag coefficient. Isolines are in $10^{-3} \mathrm{~N} \mathrm{~m}^{-2}$.

be ill-calibrated or distorted by flow interferences associated with ship superstructure. As the wind estimates are generally made by different people and vessels, the measurement uncertainties can be represented to a reasonable approximation as uncorrelated normal noise. Note that the biases associated with changes in the Beaufort scale (Cardone et al. 1990) should vary little during the short time period considered here and hence have little influence on the wind stress variability, which is of most relevance to this study. Aliasing also contaminates the pseudostress monthly means in areas of poor sampling. Sampling theory shows that it can also be treated, to a good approximation, as uncorrelated normal noise, so that the pseudostress error covariance matrix is tridiagonal (the pseudostress components are correlated), and it can be estimated by dividing the sample variances and covariances at each grid point by the number of observations. As Servain et al. (1985) did not calculate covariances, the latter were estimated for 1981 from the sample variances, using the averaged correlation between the pseudostress components during 1982-84.

The pseudostress uncertainties were simulated using a Monte Carlo approach: 25 independent realizations of the pseudostress field, consistent with its sample mean and error covariance matrix, were constructed using a random number generator and assuming normality. The different realizations of the pseudostress fields were projected onto the EOF base used to filter the original pseudostress (section $2 \mathrm{a}$ ) and then multiplied by one of the selected drag coefficients, yielding five (reasonably smooth) independent realizations of the wind stress field for each of the five selected drag laws. In the following, we consider for simplicity that the 25 fields-which are consistent with the original ship measurements-are equally plausible and normally distributed, even though the latter assumption is only approximately valid. The sampling uncertainties are quantified at each grid point by

$$
e=\left\{\frac{1}{5} \sum_{i=1}^{5}\left[\frac{1}{5} \sum_{j=1}^{5} \frac{1}{36} \sum_{t=1}^{36}\left(\tau_{i j}^{t}-\bar{\tau}_{i}^{t}\right)^{2}\right]\right\}^{1 / 2},
$$

with

$$
\bar{\tau}_{i}^{t}=\frac{1}{5} \sum_{j=1}^{5} \tau_{i j}^{t},
$$

where $i$ identifies the drag law, $j$ the pseudostress realization, and $t$ the month. Figure $3 \mathrm{~b}$ shows that the sampling uncertainties mainly reflect the density of wind observations and are generally smaller than the drag uncertainty. Along the commercial ship lines and at the equator, the sampling uncertainties are only about $2 \times 10^{-3} \mathrm{~N} \mathrm{~m}^{-2}$; but in poorly sampled areas they exceed the drag uncertainties, reaching as much as $10^{-2} \mathrm{~N} \mathrm{~m}^{-2}$.

Monte Carlo experiments were also performed to simulate the noise in the atmospheric stability data. As they only indicated little influence on the stability correction for the wind stress, the stability uncertainty has been neglected in our analysis.

\section{d. Impact of wind stress uncertainties on model simulations}

As the variability in the tropical oceans is largely remotely forced and affected by wave propagation in the equatorial waveguide, random and systematic forcing uncertainties should have a different impact on model simulations. This was investigated by forcing the linear model of Cane (1984), after spinup, with each of the 25 wind stress fields and by considering the 1982-84 evolution of the $20^{\circ} \mathrm{C}$ isotherm depth in the region where the linear model is valid (see section $3 b$ ). The influence of the various forcing uncertainties is quantified as before by a mean rms difference: the effect of pseudostress uncertainties is obtained by averaging the dispersion of the runs corresponding to each drag law, and the effect of drag uncertainty obtained from the dispersion of their means [ see relation (4) in the following].

Figure 5a shows that the drag uncertainty causes a corresponding uncertainty in the predicted thermocline depth that ranges from about $2 \mathrm{~m}$ in the intertropical convergence zone (ITCZ) to $4 \mathrm{~m}$ in the Gulf of Guinea and to $6 \mathrm{~m}$ in the NECC retroflexion region. The large impact of the forcing uncertainties in the Gulf of 

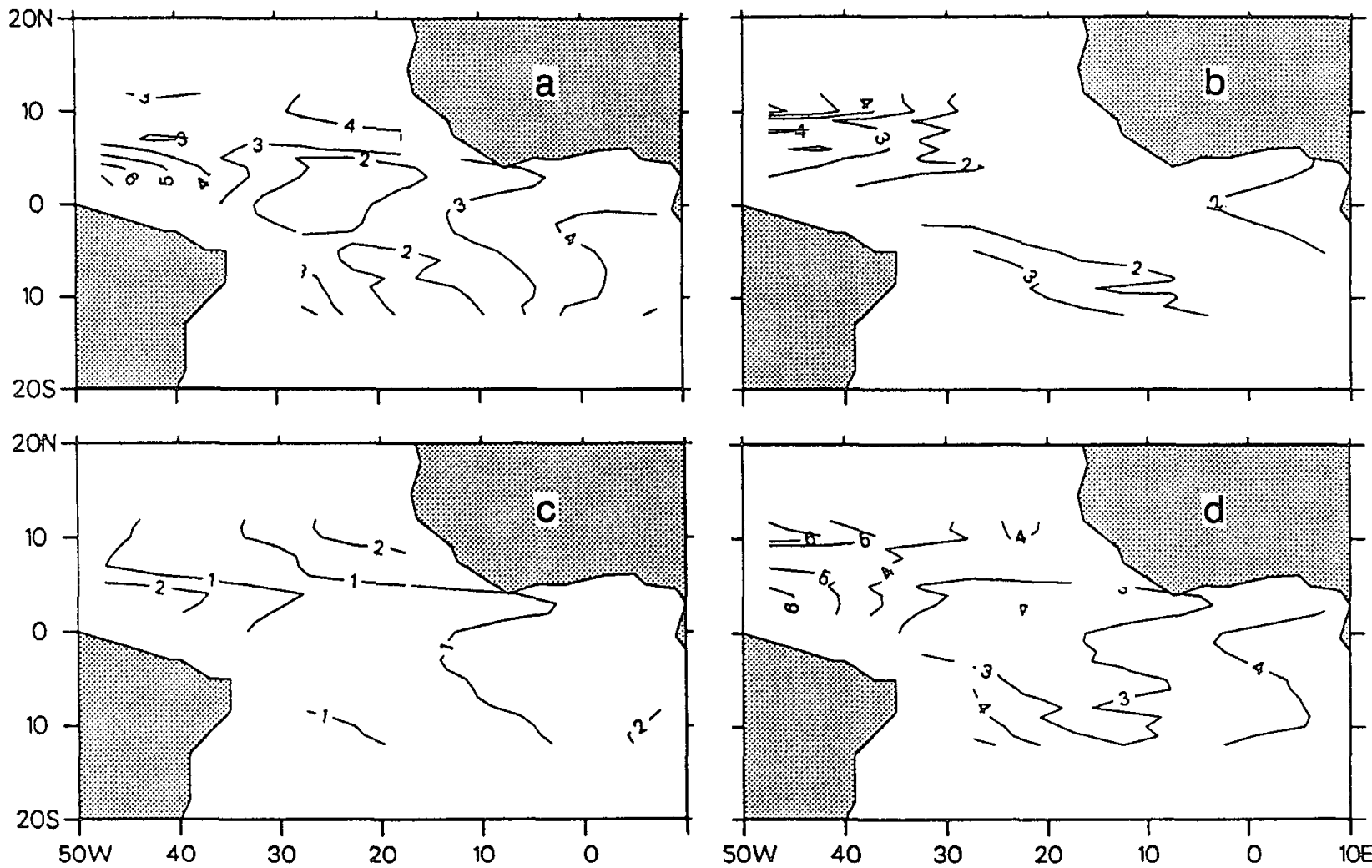

FIG. 5. Rms uncertainties (in meters) of the $20^{\circ} \mathrm{C}$ isotherm depth simulated with the linear model and caused by various sources of wind-stress uncertainties: (a) drag law, (b) pseudostress, (c) stability correction, and (d) total uncertainty.

Guinea nicely illustrates the nonlocality of the oceanic response (e.g., Houghton 1989): although the drag uncertainty tends to decrease eastward along the equator (Fig. 3a), the thermocline depth indeterminacy increases eastward because of the eastward propagation of the equatorial Kelvin waves. Similarly, some evidence of Rossby wave propagation is seen in the westward increase in thermocline depth indeterminacy along $4^{\circ} \mathrm{N}$. Similar signatures also appear in Fig. 5b, which shows the impact of the sampling uncertainties. Although the latter nearly act as a white-noise forcing, they have a significant impact both locally and nonlocally. Note that in the poorly sampled southwestern Atlantic the effect of the sampling uncertainties exceeds that of the drag indeterminacy. The total uncertainty (Fig. 5d) is calculated by assuming that sampling and drag uncertainties are independent (which is approximately true); it is small compared to the magnitude of the simulated seasonal signal (Fig. 6a), but can be as large as its interannual variability (Fig. 6b), in particular in the ITCZ and the Gulf of Guinea. This shows that even for a highly sampled period like the F/S experiment in the tropical Atlantic, the forcing uncertainties are large and should be taken into account into model-reality comparisons.

For completeness, we show in Fig. 5c the error in the oceanic response caused by neglecting the stability dependence of the drag coefficient. Although it is smaller than the effect of the forcing uncertainties, as noted earlier, it is by no means negligible, which confirms that the stability correction should not be neglected in tropical wind stress estimates.

It should be pointed out that our error analysis does not take into account the effect of the limited grid resolution, which should significantly affect the wind stress curl. As the various wind stress fields were calculated on a $2^{\circ} \times 5^{\circ}$ grid, their curl is dramatically smoothed, and model wind-driven currents such as the NECC could correspondingly be shifted in position and strength, even when averaged over a similar grid. Lacking more accurate wind stress data, however, we cannot quantify this impact.

\section{Evolution of the thermocline depth during 1982-84}

\section{a. The observations}

The FOCAL/SEQUAL experiment during 198284 has provided the most complete dataset to date of the equatorial Atlantic. It was designed to synoptically observe the upper 500 meters of the ocean in order to measure and model the oceanic response to the seasonal wind forcing. The $\mathrm{F} / \mathrm{S}$ data are thus particularly well suited for testing numerical models. Here we focus 

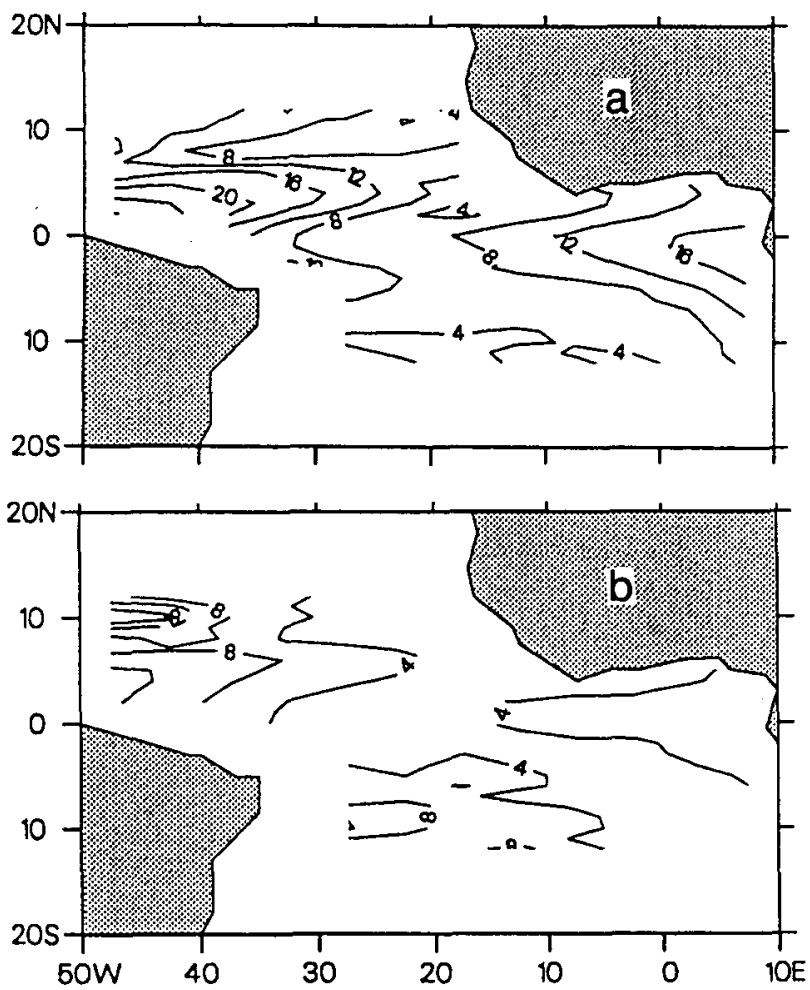

Fig. 6. Simulated (a) seasonal and (b) interannual variability of the $20^{\circ} \mathrm{C}$ isotherm depth ( $\mathrm{rms}$ in meters).

on the depth of the $20^{\circ} \mathrm{C}$ isotherm, which traces the vertical displacement of the thermocline except possibly during summer in the Gulf of Guinea where it can be very close to the surface.

Reverdin et al. (1991) made a careful analysis of the low-frequency variability of the $20^{\circ} \mathrm{C}$ isotherm depth, using all the available measurements of temperature (XBT, moored data, hydrographic sections). Although the sampling was good, gaps were numerous and the data mainly distributed along ship routes (Fig. 7). The data were interpolated using an objective function fitting, which allowed us to establish the most likely projection of the observations on a set of prescribed orthogonal functions. In space, the prescribed structures were mainly extracted from an early simulation with the LODYC GCM (seven structures) and from an analysis of the mean seasonal cycle of the surface dynamic topography (three structures), and completed by three basic structures designed to ensure a sufficiently complete representation of the observations; in time, the signal was decomposed into harmonics with periods longer than or équal to three months. The noise covariance matrix was estimated using data from moored time series and from closely spaced XBTs, assuming that zonal, meridional, and time dependences could be separated [ see Reverdin et al. (1991) for details]. This analysis provides monthly fields of the $20^{\circ} \mathrm{C}$ isotherm depth on a $1^{\circ} \times 5^{\circ}$ grid, as well as their error covariance matrix, and it was therefore selected for our purposes. As discussed in section 5, that some of the spatial structures used to fill in gaps in the observations were derived from one of the models we consider seems to have very little influence on the results.

The behavior of the analyzed fields is illustrated in Fig. 8 (left), in the domain where Cane's (1984) linear model (see below) is believed to be realistic. The evolution of the depth of the $20^{\circ} \mathrm{C}$ isotherm is dominated by the seasonal cycle. From May to November, there are strong zonal and meridional gradients in thermocline depth and an equatorially trapped upwelling, which develops first in the central Atlantic and then about one month later in the Gulf of Guinea, peaking in June-July. From December to April, there is a redistribution of mass across the basin, and the thermocline slope is flatter. Interannual variability is also present; for example, the uplift of the thermocline associated with the development of the equatorial upwelling occurred in June in 1983, but one month later in 1984. Also, the topography was particularly flat and the thermocline unusually deep in the east in early 1984 during the "Atlantic El Niño" (Philander 1986), while during the second part of the year the seasonal
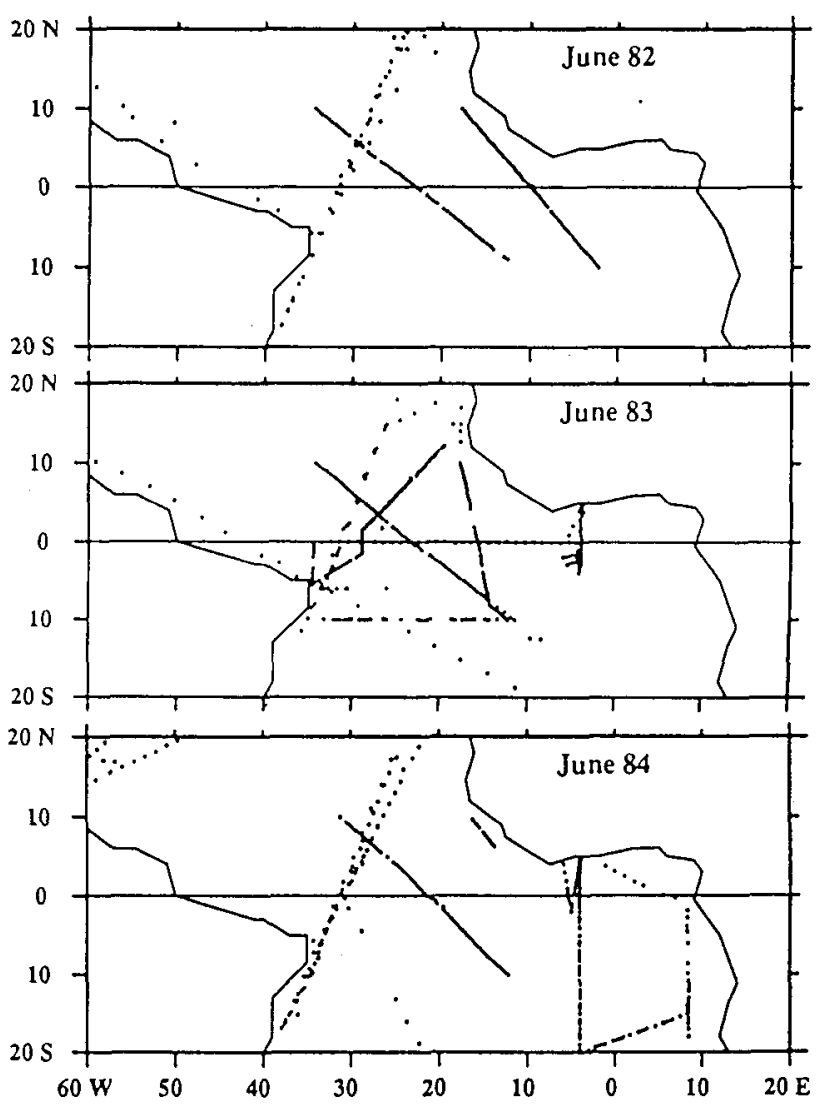

Fig. 7. Distribution of the temperature profiles used to estimate the depth of the $20^{\circ} \mathrm{C}$ isotherm in June 1982,1983 , and 1984 . 

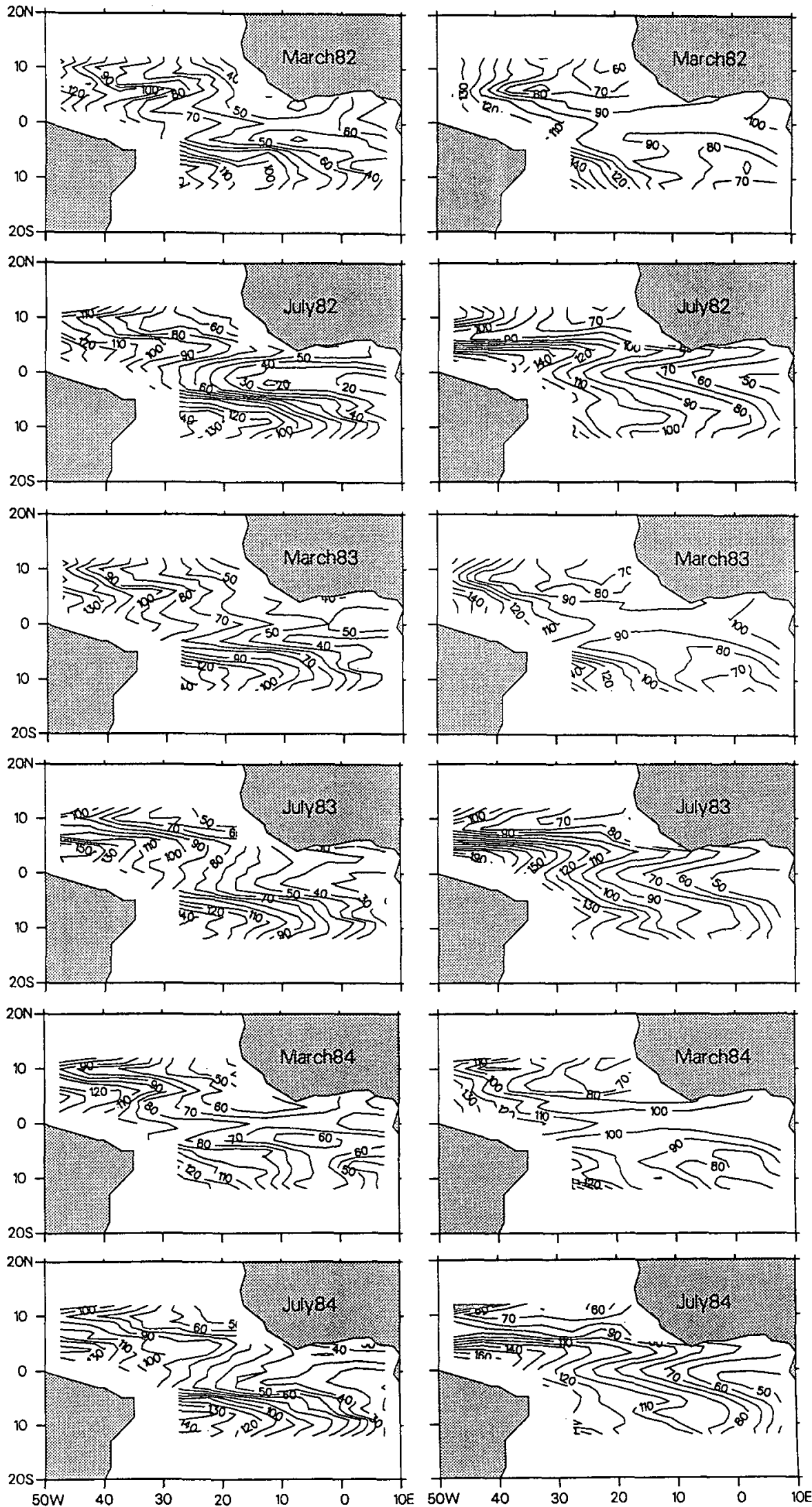
variations were much more intense and contrasted than in 1983.

\section{b. Simulations with the linear multimode model}

First, we consider simulations of the depth of the $20^{\circ} \mathrm{C}$ isotherm with the linear model of Cane (1984). It is an equatorial $\beta$-plane model with $M$ vertical modes calculated from a climatological mean density profile characteristic of the equatorial Atlantic (Blumenthal and Cane 1989). The isotherm displacement $z$ is calculated by using an isopycnal model for the vertical structure equation and setting

$$
z(x, y, \theta, t)=z_{0}(\theta)+\sum_{n} z^{\prime}(x, y, t) G_{n}(\theta),
$$

where $\theta$ is the density (or temperature), $G_{n}(\theta)$ the vertical mode for the vertical velocity, and $z_{0}$ the basicstate profile. With appropriate linearization, the vertical structure equation in density coordinates is the same as in vertical coordinates. Here only the first three baroclinic modes are considered, with phase speed of $2.36 \mathrm{~m} \mathrm{~s}^{-1}, 1.38 \mathrm{~m} \mathrm{~s}^{-1}$, and $0.89 \mathrm{~m} \mathrm{~s}^{-1}$. Grid spacing is $1^{\circ}$ in latitude and $0.5^{\circ}$ in longitude, and the time step is 10 days. The model is in the long-wave approximation and does not reproduce the western boundary circulation where the short eastward-propagating Rossby waves are dominant; the domain of study is thus limited to the region presented in Fig. 8, on the observational grid.

The model was first spun up during 10 years and then forced by each of the 25 plausible, but statistically independent, wind stress fields for the 1981-84 period. The uncertainty in the initial conditions is simulated simply by starting each run in 1981 , one year before the intercomparison period (1982-84). As the model is initially in a seasonally varying equilibrium state, one year leaves ample time for its adjustment to the applied forcing, at least in the equatorial band, so that the dispersion of the model states at the beginning of the test period should reflect realistically our lack of knowledge of the initial conditions. Thus, we have 25 independent realizations of the model $20^{\circ} \mathrm{C}$ isotherm depth during 1982-84 that simulate the scatter in model response that is expected from the forcing uncertainties. The sample average $\hat{\mathbf{m}}$, which is an $N(224$ grid points) times $T$ ( 36 months) dimensional vector that represents the space-time behavior of the model prediction, and the associated error covariance matrix $M$ provide our best estimate of the model response to the (unknown) true forcing. As before, the errors due to drag indeterminacy and to sampling uncertainties are assumed to be independent, and the error covari- ance matrix is estimated by the sum of two matrices $\mathbf{M}_{1}$ and $\mathbf{M}_{2}$, given by

$$
\begin{aligned}
& \mathbf{M}_{1}=\frac{1}{4} \sum_{i=1}^{5}\left(\overline{\mathbf{m}_{i}}-\hat{\mathbf{m}}\right)^{\prime}\left(\overline{\mathbf{m}_{i}}-\hat{\mathbf{m}}\right) \\
& \mathbf{M}_{2}=\frac{1}{5} \sum_{i=1}^{5} \frac{1}{4} \sum_{j=1}^{5}\left(\mathbf{m}_{i j}-\overline{\mathbf{m}_{i}}\right)^{\prime}\left(\mathbf{m}_{i j}-\overline{\mathbf{m}_{i}}\right),
\end{aligned}
$$

where $i$ identifies the drag law, $j$ the pseudostress realization, the overbar indicates the average for a given drag law, the caret the overall mean over all drag laws, and the prime the vector transpose. These covariance matrices have, respectively, $n_{1}=4$ (number of drag laws minus one) and $n_{2}=20$ (number of pseudostress realizations for a fixed drag law minus one times the number of laws) degrees of freedom, so that $\mathbf{M}$ has at most 24 degrees of freedom.

The comparison between simulations and observations (Fig. 8) shows that the dominant features of the 1982-84 evolution of the isotherm depth are well reproduced; however, some discrepancies are noticeable. For instance, the thermocline is often deeper in the model than in the observations, the mean equatorial slope less pronounced, and the meridional gradient across $5^{\circ} \mathrm{N}$ larger during the second part of the year. In view of the simplicity of the linear model, and in particular the coarseness of its representation of frictional processes (by a Rayleigh friction), systematic differences with the observations are expected for the long-term mean. Figure 9 shows indeed that some of the discrepancies, like the larger depth of the thermocline, appear in the 3-year mean. Since the multimode model is primarily aimed at simulating the variability of the tropical oceans [it is used in the anomaly mode in Zebiak and Cane (1987)], the 3-year means have been substracted from the fields, so that only observed and simulated departures from the mean conditions are considered in the remainder of this paper.

These departures are illustrated Fig. 10 (left and middle). The main seasonal variations and, in particular, the late spring uplift of the thermocline at the eastern coast are well reproduced, but the variability farther west is less faithfully simulated. Also, the model has less interannual variability than the observations, and the large year-to-year fluctuations in upwelling magnitude, in particular during the March 1983 event, are not well reproduced. However, straightforward visual comparison cannot indicate whether the modelobservation differences (Fig. 10, right) are due to model deficiencies or to forcing uncertainties and observational errors, so that a more quantitative comparison is needed. 


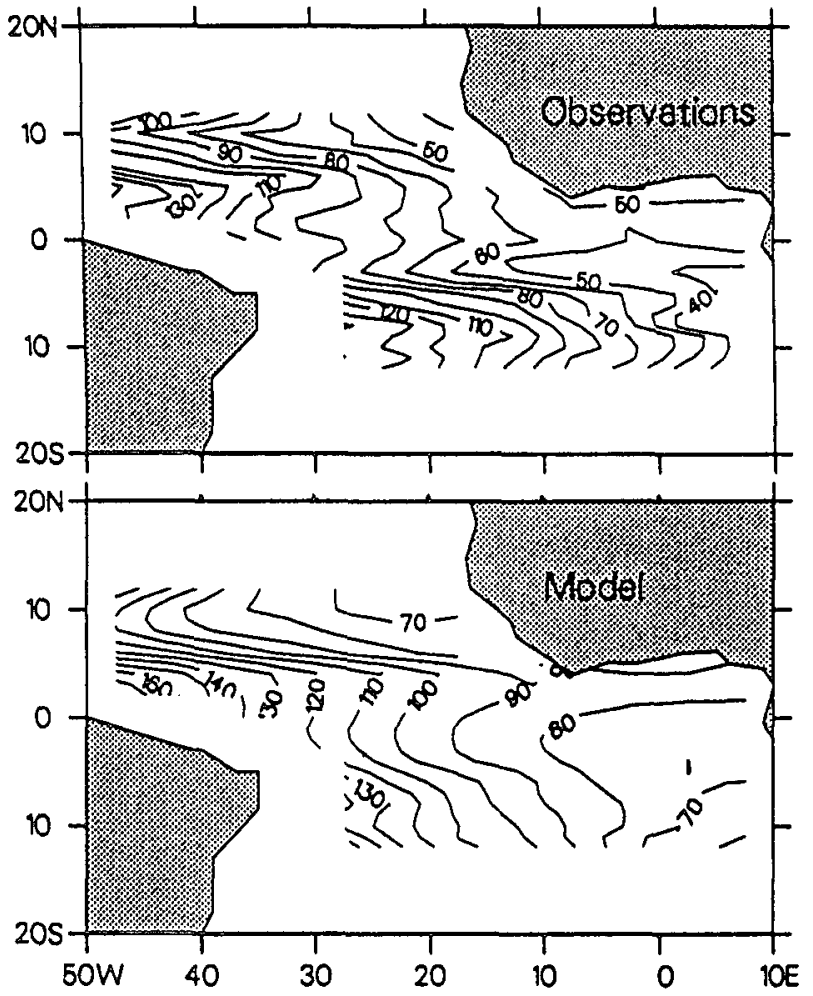

FIG. 9. Three-year mean for the observed and the simulated signals.

\section{The testing procedure in the time-series case}

To distinguish between model and data errors and to quantify model-data agreement, Frankignoul et al. (1989) have developed an objective procedure where the equality between the multidimensional observed and simulated fields is tested at a given level of significance, taking into account the uncertainties in the oceanic observations and the atmospheric forcing. The method was developed for testing model simulations of the mean seasonal variability, and has been successfully applied to various oceanic variables and models. It is extended here to the time-series case (interannual variability) in the context of the $20^{\circ} \mathrm{C}$ isotherm depth evolution during F/S; however, the formulation is general and could be readily applied to other cases.

\section{a. Test formulation}

Let the $N \times T$ dimensional vectors $\mathbf{d}$ and $\hat{\mathbf{m}}$ denote our estimate of the observed and modeled space-time behavior of the $20^{\circ} \mathrm{C}$ isotherm depth during $\mathrm{F} / \mathrm{S}$, respectively. Because of observational uncertainties, d differs from the true oceanic state $\langle\boldsymbol{d}\rangle$ and $\hat{\mathbf{m}}$ differs from the model response to the true forcing $\langle\mathbf{m}\rangle$. If $D$ denotes the error covariance matrix of the observed state and $\mathbf{M}=\mathbf{M}_{1}+\mathbf{M}_{2}$ (section $3 \mathrm{~b}$ ), our estimate of the error covariance matrix of $\hat{m}$ due to forcing uncertainties, we define the misfit

$$
T^{2}=(\mathbb{d}-\hat{\mathbf{m}})^{\prime} \mathbf{S}^{-1}(\mathbf{d}-\hat{\mathbf{m}}),
$$

with $S=\mathbb{D}+M$, which provides a measure of the differences between the two fields relative to the data accuracy, and can be interpreted as a signal-to-noise ratio. If the two fields can be considered as multinormal, the null hypothesis that $\langle\mathrm{m}\rangle=\langle\mathbb{d}\rangle$ (there is no model error) can be tested in principle by considering the statistic (5). Indeed, if the null hypothesis holds, the distribution of (5) can be approximated by Hotelling's $T^{2}$ with $\mu=N \times T$ (the dimension of the space) and $\nu$ degrees of freedom, where $\nu$ is the degrees of freedom of $\mathfrak{S}$, which can be estimated, following Yao (1965), by

$\frac{1}{\nu}=\sum_{i=1}^{2} \frac{1}{n_{i}-1}\left(\frac{(\mathbb{d}-\hat{\mathbf{m}})^{\prime} \mathbf{S}^{-1}\left(\mathbf{M}_{i} / n_{i}\right) \mathbf{S}^{-1}(\mathbb{d}-\hat{\mathrm{m}})}{(\mathbb{d}-\hat{\mathbf{m}})^{\prime} \mathfrak{S}^{-1}(\mathbb{d}-\hat{\mathrm{din}})}\right)^{2}$,

where $n_{1}$ and $n_{2}$ are the degrees of freedom of $m_{1}$ and $\mathbf{M}_{2}$. For simplicity, we have assumed that $D$, given by Reverdin et al.'s ( 1991) error analysis, is the true error covariance matrix of the observations (rather than an estimate), and thus has infinite degrees of freedom. The distribution of (5) is related to the $F$ distribution with $\mu$ and $\nu-\mu+1$ degrees of freedom by $T^{2}=[\mu \nu /$ $(\nu-\mu+1)] F$. If $T^{2}$ is superior to its critical value at a given level of significance the null hypothesis is rejected, and it should be concluded that there are model errors. More precisely, as no model can be expected to be perfect, it should be concluded that the observations are sufficiently accurate, and the forcing sufficiently known, to detect model deficiencies.

In practice, the dimension of the space $\mu$ is very large, whereas M, estimated from the available model simulations, has limited degrees of freedom (at most 24 in the present case). Furthermore, although has been assumed to represent the true error covariance matrix of the observations, it is only known approximately, and its details cannot be trusted. Thus, the matrix $S=D$ is not known accurately in the whole $\mu$ space and it is of reduced rank. Even if it can be calculated, its inverse is dominated by unreliable information, and the test cannot be applied unless the dimensionality of the system is strongly reduced. An essential step of the model testing procedure is thus to test the model in a strongly reduced space that represents only the main space-time patterns of both observations and simulations; small-scale variations are not reliably represented, and they must be filtered out for a proper statistical treatment.

The data compression is performed using common principal component analysis (hereafter common PC). This method, developed by Flury (1989), is particularly efficient at extracting the main patterns of variability of both observed and simulated fields, thereby allowing 
a strong reduction in dimensionality while keeping most of the variance of the two fields [see Duchêne and Frankignoul (1991) for details].

\section{b. Data compression in the spatial domain}

Common PC analysis is first used to define the main orthonormal spatial patterns of variation (common EOFs) of the observed and the simulated fields. Table 1 shows that only four common EOFs (shown in Fig. 11 , left, and referred to as CPC1, CPC2, CPC3, and CPC4) are needed to describe about $80 \%$ of the variance of the two fields. The common EOFs have large spatial scales, and their temporal behavior is coherent, as shown in Fig. 11 (right) where the observations are represented by a continuous line and the simulations by a dotted line. The univariate $95 \%$ confidence intervals are estimated from the diagonal terms of the error covariance matrices in the reduced space, providing a first quantitative view of the importance of the data uncertainties, although they must be interpreted with caution as the errors are correlated in space and time. The first common EOF primarily describes the zonal redistribution of mass across the basin, which occurs at the annual period. Model and observations are in good agreement in this subspace with a 0.92 correlation between the two time series, although the simulated variations have a larger amplitude. The second common EOF describes a latitudinal redistribution of mass and the occurrence of equatorial upwelling, and it has mainly annual and semiannual variations, peaking during the upwelling season in June-July. There is also a good correlation $(0.81)$ between the projection of the observed and simulated fields onto that structure, but here the simulated variations have a smaller amplitude; note also the differences in early 1983 . The third common EOF describes systematic differences between model and observations, as the two time series are nearly out of phase. This is not unexpected from common PC analysis, as it tries to best project two fields onto a small number of spatial patterns, thereby favoring either in-phase or out-of-phase behaviors. The fourth common EOF is somewhat more noisy, while the higher structures that were filtered out (not shown) show an increasing amount of noise in both space and time.

This first data compression has reduced the dimension of the intercomparison space from $216 \times 36$ to 4 $\times 36$. This is still too large, and a further data compression is needed.

\section{c. Data compression in the time domain}

In the seasonal case (Frankignoul et al. 1989), the time dimension was 12 (monthly means) and data compression was limited to considering only seasonal means. In the time-series case, the time dimension can be much larger, and a more drastic data compression is needed. This is done by also using common PC analysis in the time domain, that is, by determining the main temporal behaviors that are common to both observations and simulations in reduced space. The procedure is powerful and could be easily applied to much longer series than considered here.

As in principal component analysis, common EOFs are derived from the covariance matrix of the variations around the sample means (here the spatial means in reduced space, i.e., the mean of the four observed and simulated time series in Fig. 11, respectively); hence, they efficiently represent the (spatial) fluctuations around those means, but not necessarily the spatial means themselves. In our case, three orthonormal vectors ( the common EOFs in the time domain, denoted by $\mathrm{T} 1, \mathrm{~T} 2$, and $\mathrm{T} 3$ in Table 2 ) suffice to represent most of the variance of the observed and simulated temporal variations in reduced space. The first temporal common EOF represents an annual signal with somewhat varying amplitude over the 3-year period (Fig. 12, left) that, not surprisingly, resembles the temporal behavior of observations and simulations in the space of the first spatial common EOF (Fig. 11, right); correspondingly, the dominant spatial structure that has this temporal evolution is the first spatial common EOF for. both observations and the model [represented in Fig. 12 (right) by continuous and dotted lines]. The second temporal common EOF represents more complex variations with a strong change in 1984, and it is not unlike (but out of phase with) the observed and simulated behaviors in the space of the second spatial common EOF; correspondingly, the maximum (negative) amplitudes are found for the second spatial common EOF. The third temporal behavior is more noisy and cannot be associated with a particular spatial structure.

As expected, the temporal evolution of the observed and simulated spatial means in reduced space (see above) poorly project onto these three orthonormal temporal patterns $(64 \%$ and $61 \%$ of the variance for the observations and the simulations, respectively), and the temporal base needs to be extended to represent the whole signal. This is done in two steps, since the observed and simulated means have a different temporal evolution. The orthonormal base is completed by adding first the normalized part of the observed mean evolution that does not project onto the three vectors $T 1, T 2$, and $T 3$ above and then adding the normalized part of the simulated mean evolution that does not project onto the extended space (the two vectors are referred to as $\mathrm{T} 4$ and $\mathrm{T} 5$ in Table 2).

In summary, Fig. 12 (right) shows how the four spatial structures (in reduced space) behave in the reduced temporal space, with univariate error bars estimated as previously. The figure clearly shows that observations and simulations are not entirely consistent, as the magnitude of the error bars is much smaller than their difference. 
TABLE 1. Percentages of variance represented by the first four common EOFs in the spatial data compression (linear model).

\begin{tabular}{lccccc}
\hline & $\begin{array}{c}\mathrm{CPC} 1 \\
(\%)\end{array}$ & $\begin{array}{c}\text { CPC2 } \\
(\%)\end{array}$ & $\begin{array}{c}\text { CPC3 } \\
(\%)\end{array}$ & $\begin{array}{c}\text { CPC4 } \\
(\%)\end{array}$ & $\begin{array}{c}\text { Total } \\
(\%)\end{array}$ \\
\hline $\mathbf{d}$ & 36.7 & 28.9 & 5.7 & 8.1 & 79 \\
$\hat{\mathbf{m}}$ & 57.6 & 11.5 & 10.8 & 2.7 & 82 \\
\hline
\end{tabular}

\section{d. The test}

A strong data compression, from $\mu=224 \times 36$ $=8064$ to $\mu=4 \times 5=20$, has been achieved, and the null hypothesis that the model response is consistent with the oceanic observations can now be tested. The value of $T^{2}$ is found to be 1103 , with degrees of freedom $\nu=450$. For such large degrees of freedom, $T^{2}$ approximately behaves like a chi-squared distribution with $\mu=20$ degrees of freedom, and the critical value at the $5 \%$ level of significance is 34 . The null hypothesis is thus rejected, which confirms that forcing and observation uncertainties cannot solely explain the model-reality discrepancies.

Similar results were found when testing the linear model with observations of the mean seasonal cycle of surface dynamic topography, which similarly reflects the changes in thermocline depth (Duchêne and Frankignoul 1991). The results are not directly comparable, however, as (5) has been estimated in subspaces of different dimension, and the two datasets have different uncertainties [remember that (5) is a measure of the model-observation discrepancies weighted by the data uncertainties ]. It is nonetheless of interest to attempt a comparison between the two analysis in order to determine which dataset is most appropriate for model validation.

For this purpose, consider the statistics (5). In both cases the null hypothesis is rejected and $\mu$ is large. Under these conditions, the distribution of (5) can be approximated by a noncentral chi-square $\left[\chi_{\mu}^{2}(\lambda)\right]$ distribution with $\mu$ degrees of freedom and noncentrality parameter $\lambda$, and $T^{2}$ is the best estimator of $\lambda$ (e.g., Seber 1984). As $\lambda$ is large, the variable

$$
\frac{\chi_{\mu}^{2}(\lambda)-(\lambda+\mu)}{[2(\mu+2 \lambda)]^{1 / 2}},
$$

where $\mu+\lambda$ and $2(\mu+2 \lambda)$ represent respectively the mean and the variance of the noncentral $\chi^{2}$ distribution, has, to a good approximation, a unit normal distribution. The two analysis can thus be compared by dividing the respective misfits by $[2(\mu+2 \lambda)]^{1 / 2}$, which provides a standardized measure, say $T_{s}^{2}$, of the noncentrality of the test statistics. The results are found to be $T_{s}^{2}=11.3$ and $T_{s}^{2}=16.5$ for dynamic topography and thermocline depth, respectively, so that the misfit is significantly larger in the F/S case. It cannot be said, however, whether the larger sensitivity of the F/S data is due to less forcing and observational uncertainties or to the presence of a marked interannual variability that had to be well simulated.

The same conclusion holds when comparing the performances of the linear model with two and three vertical modes. Duchêne and Frankignoul (1991) showed that the performances of the model seemed best with three modes; however, the two-, three-, four-, and five-vertical-mode versions could not be statistically differentiated with the dynamic topography data. Using the $\mathrm{F} / \mathrm{S}$ data, we find that the misfit, $T^{2}$ $=1390\left(T_{s}^{2}=18.6\right)$, is significantly larger at the $5 \%$ level when the linear model has only two vertical modes, so that the three-mode version should indeed be preferred. This confirms that the $\mathrm{F} / \mathrm{S}$ dataset is a very accurate one for model testing and tuning.

\section{e. Test in the equatorial waveguide}

As the modal structure of the linear model is representative of the equatorial stratification, but not of the extra-equatorial regions where the thermocline is deeper, the multimode model could perform better in the vicinity of the equator. On the other hand, nonlinearities and mixing processes are more important near the equator, but the former are not represented, and the latter only crudely parameterized. It is thus of interest to test the linear model in the equatorial waveguide, taken to be $3^{\circ} \mathrm{N}-3^{\circ} \mathrm{S}$. Because of the smaller extent, the data compression can be more drastic, and only three spatial eigenvectors are needed, accounting for $90 \%$ (95\%) of the observed ( simulated) field. The spatial structures are similar to those of the whole domain, but the first two patterns have a substantial semiannual variability (Fig. 13). Model and observations are again in phase in the space of the first two common EOFs, with a correlation of 0.84 and 0.87 , respectively. The third pattern emphasizes the modelreality differences, with maximum amplitude in late 1983 and mid-1984. The test yields $T^{2}=947$, for a critical value of 23.3 , which is slightly smaller than, but not significantly different from, the misfit in the full domain (Fig. 14). Since the observational errors are likely to be of same order throughout the region, it can be concluded that the model does not perform statistically better near the equator than in the whole $12^{\circ} \mathrm{N}-12^{\circ} \mathrm{S}$ region. This contrasts with the results of McPhaden et al. (1988) and Harrison et al. (1989), who found that model-reality agreement in the Pacific was better in the equatorial waveguide. This difference may be attributed in part to the smaller extension of the Atlantic basin and the presence of the African coasts, which make the equatorial Atlantic more difficult to simulate (Blummenthal and Cane 1989); also, introducing the three-year mean in the analysis could modify our conclusion. The simulation of the F/S observations in the equatorial waveguide may also appear less realistic than in Weisberg and Tang (1990), who found good agreement between the response of a one- 

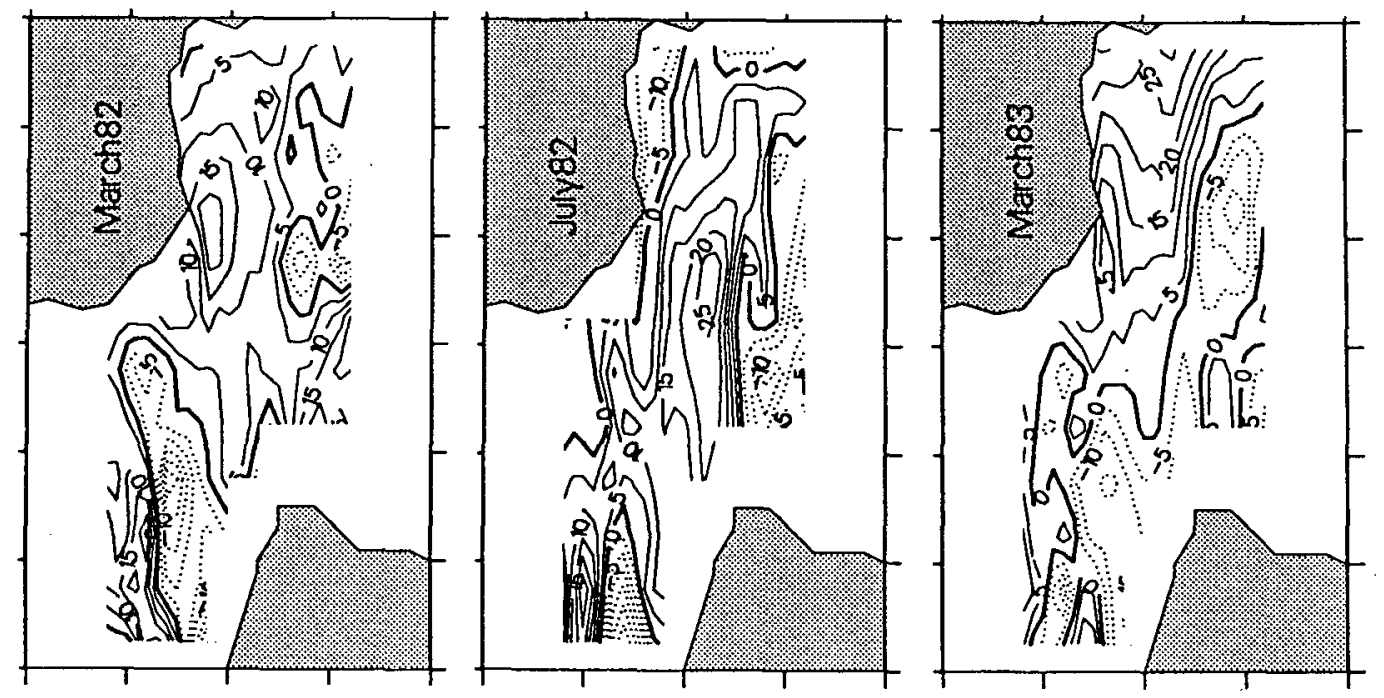

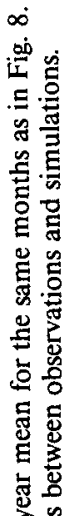
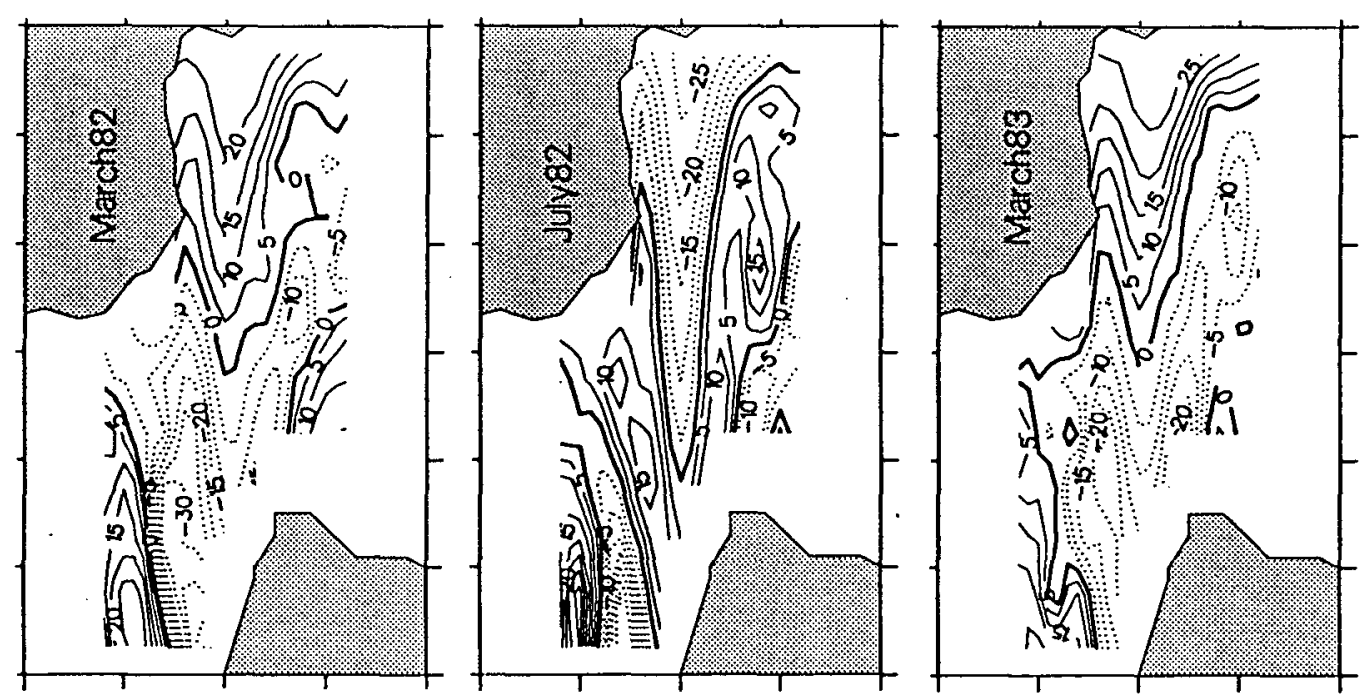

递
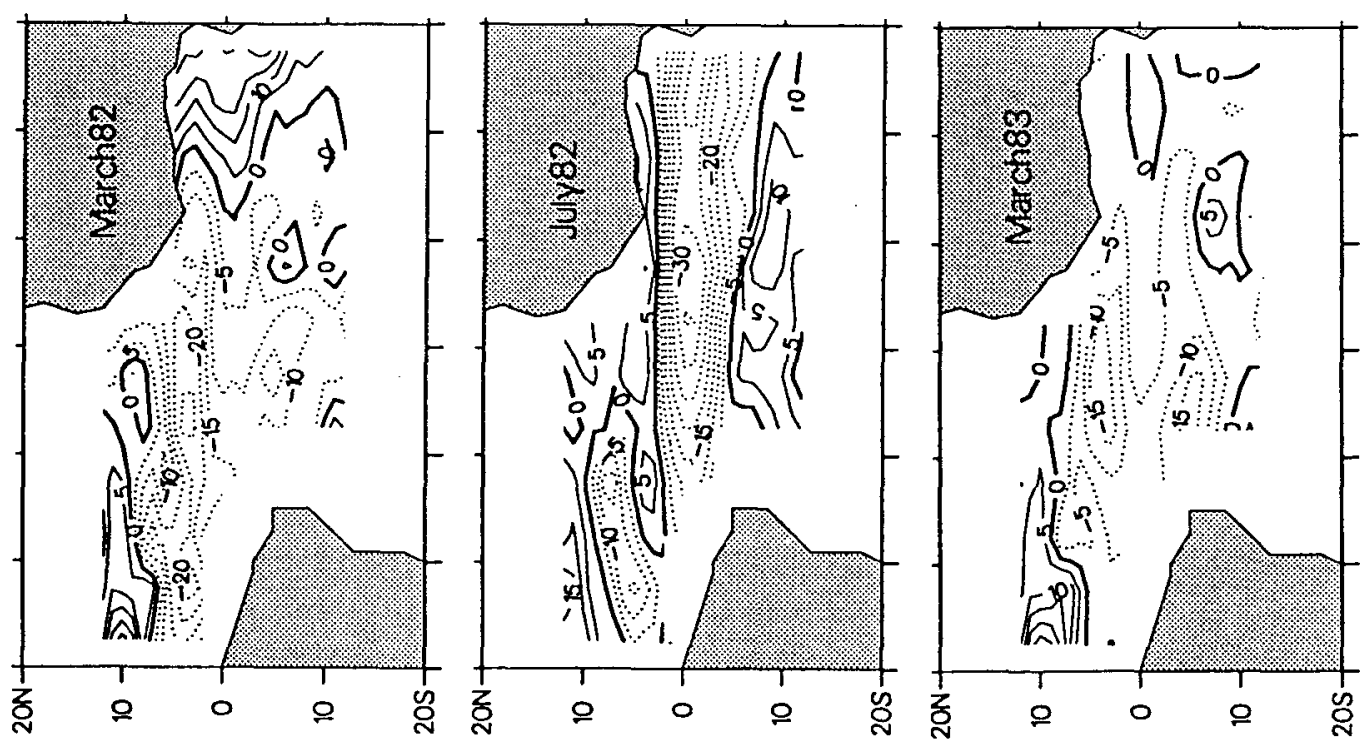

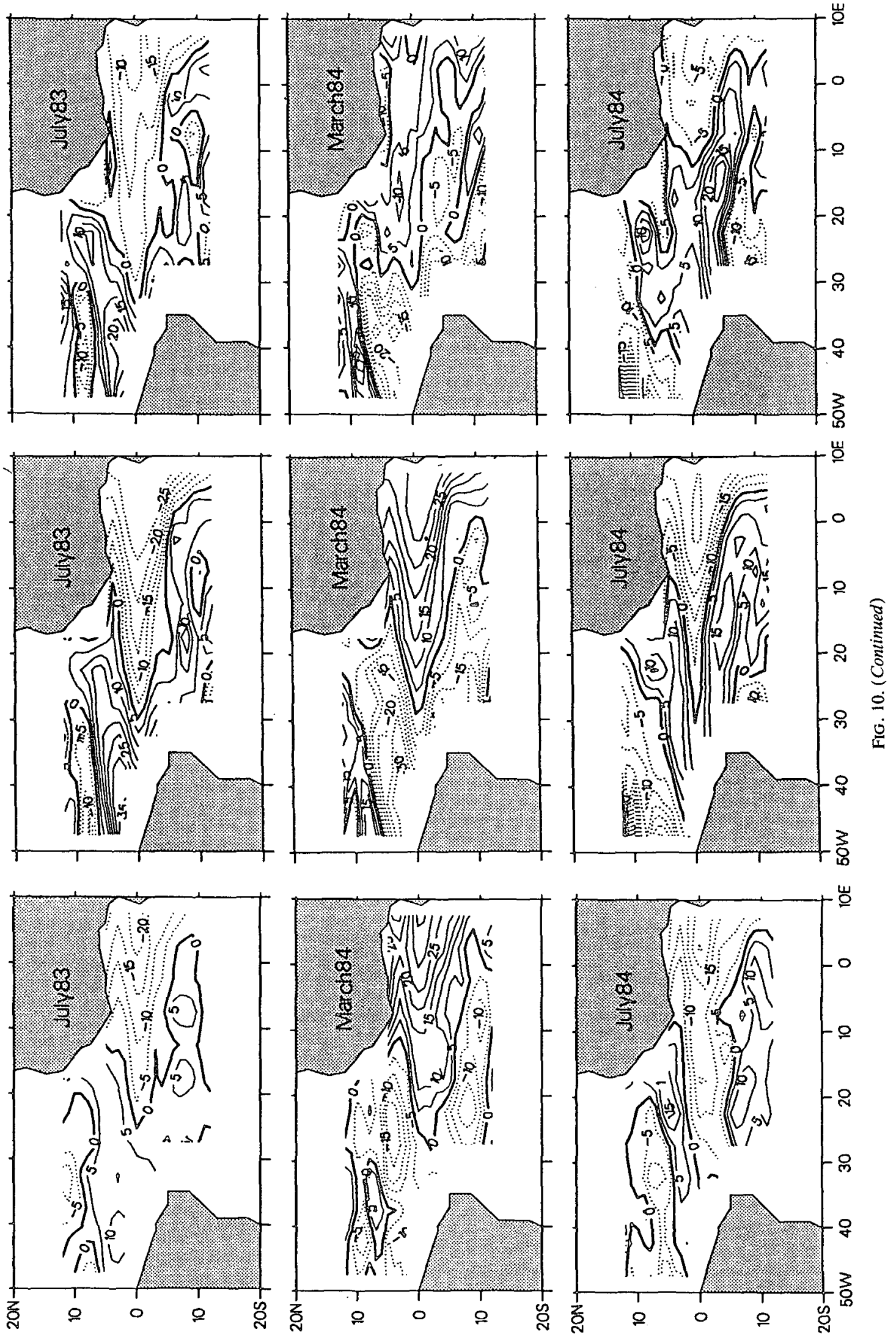

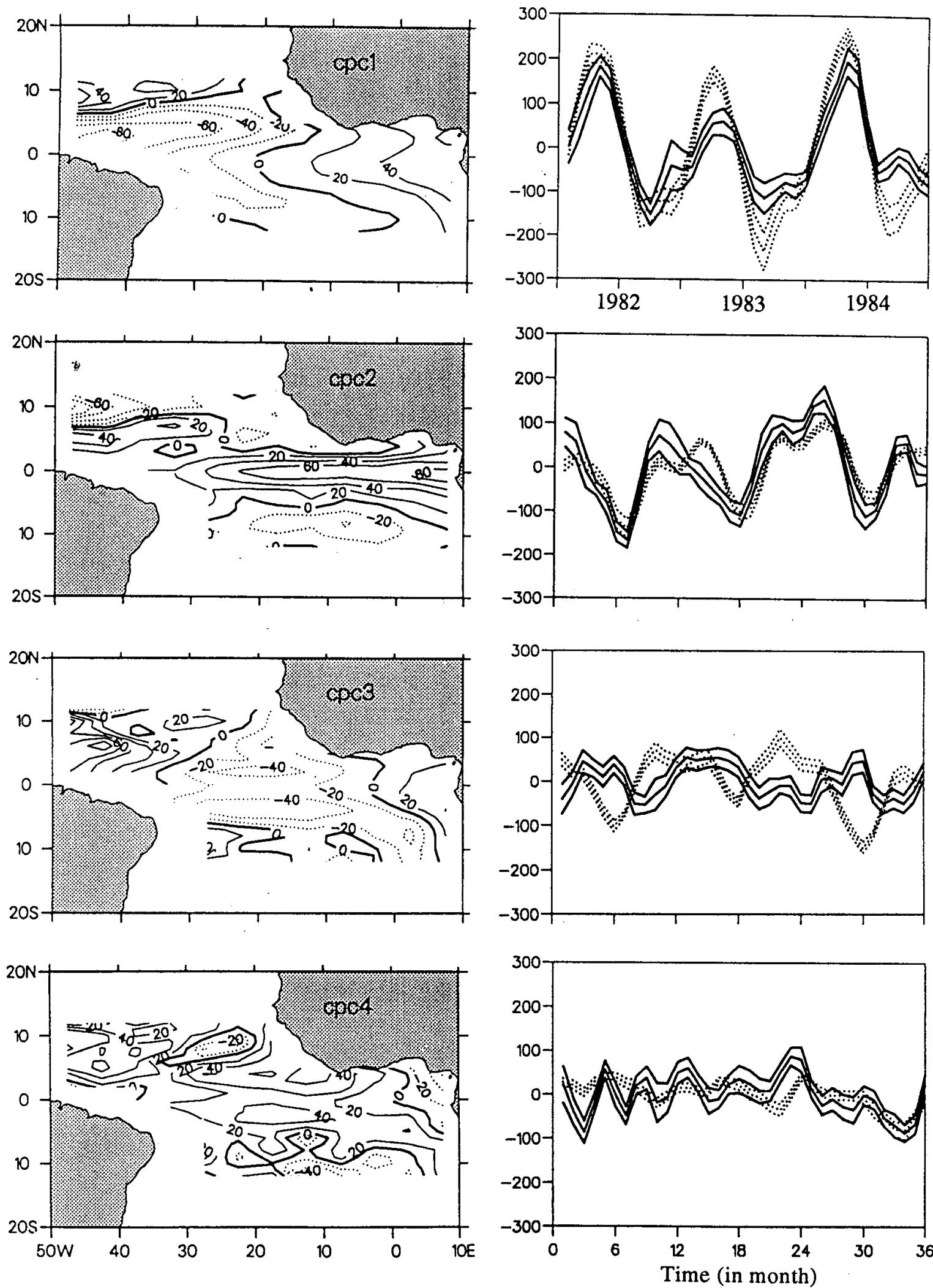

FIG. 11. Spatial common PC analysis for the linear model. Left: basis orthonormal spatial vectors. Right: projections (time series) of observed (continuous middle line) and modeled (dotted, middle line) fields onto the spatial base; time unit is month. The univariate $95 \%$ confidence intervals are estimated from the diagonal terms of the error covariance matrices in the reduced space. 
TABLE 2. Percentages of the total variance represented by the five orthonormal basis vectors in the temporal data compression (linear model). The index $r$ indicates that the calculation is done in the spatially reduced space.

\begin{tabular}{lllllll}
\hline \hline & $\begin{array}{c}\text { T1 } \\
(\%)\end{array}$ & $\begin{array}{c}\text { T2 } \\
(\%)\end{array}$ & $\begin{array}{c}\text { T3 } \\
(\%)\end{array}$ & $\begin{array}{c}\text { T4 } \\
(\%)\end{array}$ & $\begin{array}{c}\text { T5 } \\
(\%)\end{array}$ & $\begin{array}{c}\text { Total } \\
(\%)\end{array}$ \\
\hline $\mathbf{d}_{r}$ & 52.6 & 30.1 & 6.9 & 7.4 & 0.7 & 97.5 \\
$\hat{\mathbf{m}}_{r}$ & 62.3 & 18.3 & 3 & 6.8 & 6.7 & 97.5 \\
\hline
\end{tabular}

mode version of the linear model and heat content changes estimated from four equatorial moorings. However, their applied wind stress was highly idealized, and only phase relationships were considered, not amplitudes, as observed and simulated time series were normalized by their standard deviation.

\section{Toward a model intercomparison}

Since the $\mathrm{F} / \mathrm{S}$ data are accurate enough to unambiguously detect model deficiencies, they are suitable for model tuning and intercomparison. Here we discuss a preliminary analysis of the behavior of the thermocline during 1982-84 as simulated by the LODYC GCM in a 7-year run fully described in Morlière and Duchêne (1992). As only one GCM simulation was available, the forcing uncertainties could not be taken into account [ $\mathrm{M}=0$ in (5)], and the test provides only an upper bound of the GCM performances. Nonetheless, significant differences with the performances of the linear model can already be detected by the multivariate analysis procedure.

The LODYC GCM has 17 vertical levels (including 13 levels in the upper $325 \mathrm{~m}$ of the water column), a horizontal C-type grid varying in latitude from $0.3^{\circ}$ at the equator to $1.5^{\circ}$ at the north and south boundaries $\left(50^{\circ} \mathrm{N}\right.$ and $30^{\circ} \mathrm{S}$, respectively), and in longitude from $0.5^{\circ}$ near the coast to $1^{\circ}$ at the center of the basin, and there is a relaxation toward Levitus (1982) temperature and salinity climatology (for details, see Reverdin et al. 1991). In the version used by Scoffier et al. (1993), the parameterization of the vertical diffusion is that of Pacanowski and Philander (1981). The thermal fluxes were estimated from the Esbensen and Kushnir (1981) climatology. For the $1982-84$ period, the wind-stress field was that from Reverdin's merchant ship observation analysis, using the drag coefficient of Liu et al. (1979), and it is thus very similar to our LIU wind stress.

To facilitate the comparison with the linear model, we again consider the departures from the 3-year mean conditions (Fig. 15). Overall, the GCM seems to better simulate the 1982-84 thermocline variability, but there remain noticeable discrepancies with the observations. For instance, the maximum uplift of the model thermocline in summer is located in the middle of the basin; hence, it does not extend far enough eastward to- ward the African coast. Also, as with the linear model, the 1983 upwelling is not well reproduced. Note that the magnitude of the 1984 anomalous deepening of
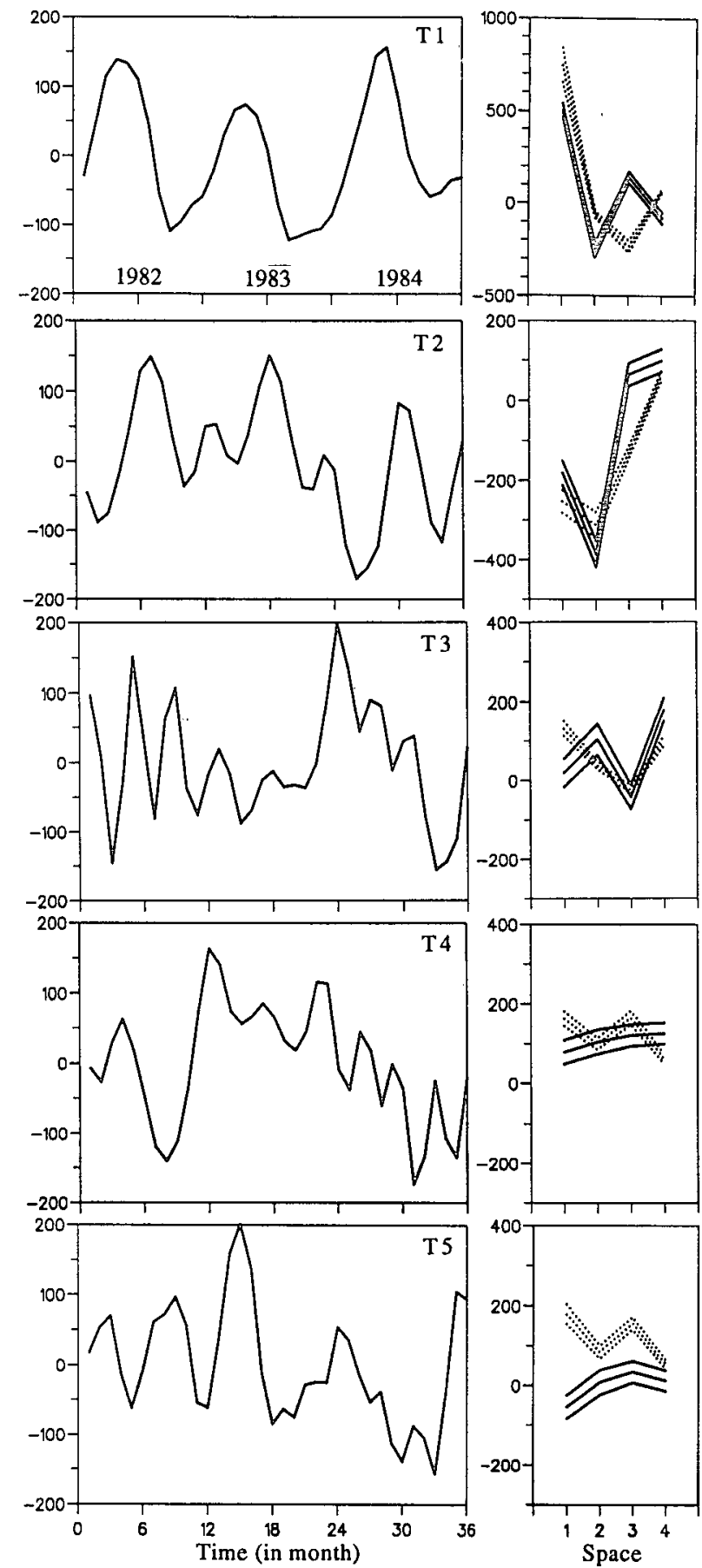

Fig. 12. Temporal common PC analysis for the linear model. Left: basis temporal vectors. Right: projections of the observed (continuous middle line) and modeled (dotted middle line) time series of Fig. 11 onto the temporal base. The four common EOFs are numbered 1 to 4 , and the univariate confidence intervals are estimated as in Fig. 11. 

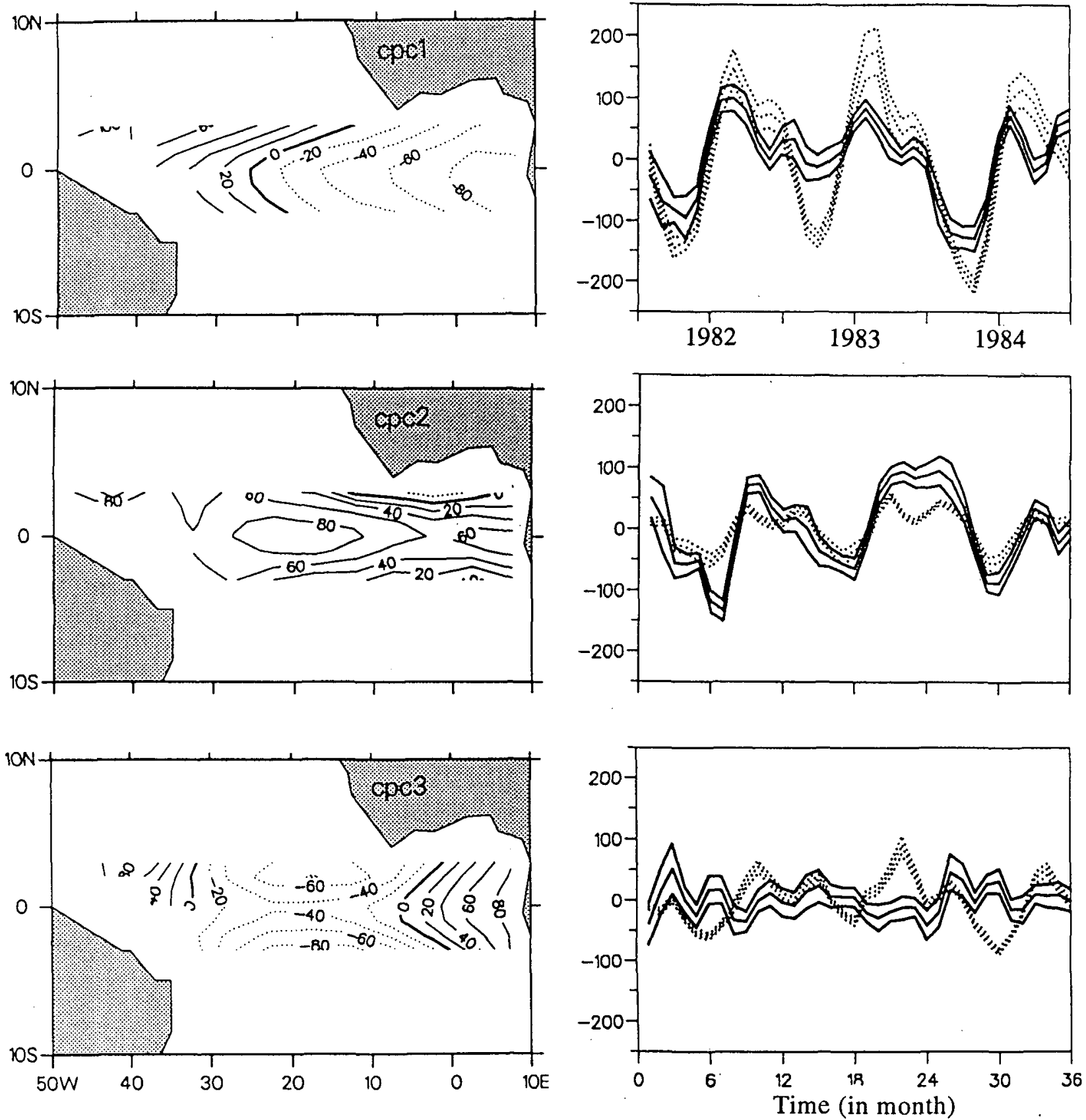

FIG. 13. As Fig. 11 but for the $3^{\circ} \mathrm{N}-3^{\circ} \mathrm{S}$ domain.

the thermocline depth in the Gulf of Guinea seems to be better simulated by the linear model.

In the $12^{\circ} \mathrm{N}-12^{\circ} \mathrm{S}$ region, the common $\mathrm{PC}$ analysis in the spatial domain yielded four structures that were distinct from noise, accounting for $78 \%$ and $76 \%$ of the observed and simulated variability, respectively (Table 3), and similar to those of the linear model (compare Fig. 11 to Fig. 16). In the space of the first two common EOFs, the GCM is in very close agreement with the observations, with correlations of 0.94 and 0.89 , respectively. The amplitudes are very similar, showing in particular that the intensity of the equatorial upwelling is better reproduced than with the linear model, even if there remain systematic differences with the observations, as noted above. The agreement deteriorates for the other two structures, model and observations being mainly out of phase in the subspace of the fourth common EOF (Fig. 16). The statistical test yields $T^{2}=660\left(T_{s}^{2}=12.7\right)$, an upper bound of the GCM performances that is much higher than the 


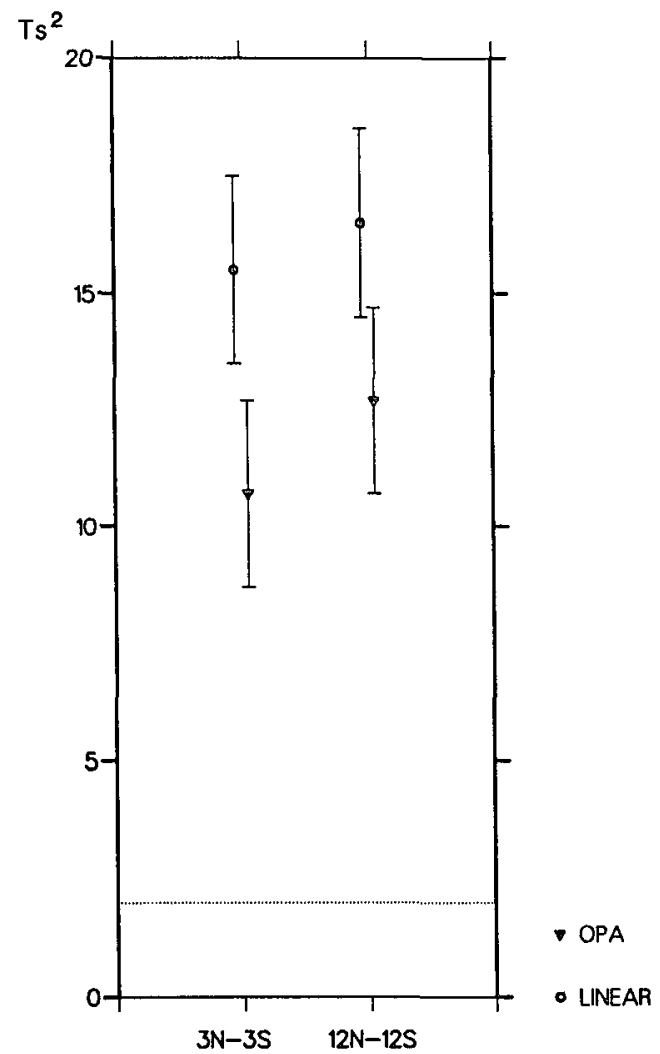

FIG. 14. Standardized value of the misfit between model and observations for the linear model and the LODYC GCM, in the $12^{\circ} \mathrm{N}$ $12^{\circ} \mathrm{S}$ and the $3^{\circ} \mathrm{N}-3^{\circ} \mathrm{S}$ regions. The error bars represent the estimated $95 \%$ confidence intervals, and the dotted line the critical value for rejecting the hypothesis of no model error. The misfits for the GCM are only upper bounds, as the forcing uncertainties are not included.

critical value of 34 , but already significantly smaller than the misfit obtained for the linear model, at the $5 \%$ level of significance (Fig. 14). A $3^{\circ} \mathrm{N}-3^{\circ} \mathrm{S}$ test $\left(T^{2}\right.$ $=467, T_{s}^{2}=10.7$ ) confirms the superiority of the GCM, which is more pronounced in the equatorial waveguide, presumably because of the representation of the nonlinearities and the better parameterization of vertical mixing. However, as for the linear model, the misfit (5) is only slightly smaller than in the whole domain, and not in a statistically significant manner.

As some of the spatial structures used to interpolate the observations were derived from a run with this GCM ( section 3a), it may be wondered whether they influence our results. However, it must be remembered that the structures derived from the GCM were completed by enough orthonormal structures to ensure a good projection of all the observations onto the prescribed basic functions (Reverdin et al. 1991), so that the observational bias is presumably small. Nonetheless, this choice of basic functions is likely to have affected some of the details of our analysis, like the exact patterns of the main common EOFs and the way the model simulations project onto them. In particular, we suspect that the very high correlation in the subspace of the first two common EOFs in Fig. 16 may be linked to the use of these structures; however, this choice also seems responsible for the deterioration in the subspace of the next two common EOFs, probably dominated by patterns not well represented in the GCM, so that there should be no net influence on the overall fit. This interpretation is substantiated by our analysis (Braconnot 1992) of an improved version of the LODYC GCM (Blanke and Delecluse 1993), whose dominant patterns of variation were not used in analyzing the observations: the correlations are found to be poorer in the subspace of the first two common EOFs but better in the subspace of the last two ones, resulting in a smaller misfit than for the GCM version tested here. Thus, as long as enough spatial structures are kept in the data compression to properly represent both the main in-phase and out-of-phase features of the observations and the simulations, we believe that the details of the observational analysis have little impact on the test.

Although the superiority of the GCM over the linear model is expected and has been detected previously through the validation of the mean seasonal cycle of surface dynamic topography (Frankignoul 1991), it is shown much more clearly in the present study. Indeed, compare the standardized misfits for the linear model and the GCM: respectively 16.5 and 12.7 (upper bound) for the F/S data, against 11.3 and 9.7 for the mean surface dynamic topography. The higher accuracy of the F/S data not only leads to a higher signalto-noise ratio but also to a clearer distinction between the model performances.

\section{Summary}

The multivariate model testing procedure of Frankignoul et al. (1989), developed for the case of the mean seasonal cycle, has been extended to the general time-series case, thus allowing to test model ability at simulating the interannual variability. The method aims at distinguishing between ocean model inadequacies and data uncertainties, and requires a detailed analysis of the observational errors and a simulation of the forcing uncertainties. As our knowledge of the data uncertainties is limited, the model performances must be evaluated in a space of reduced dimension. To efficiently perform the data compression while representing the dominant space-time patterns of the observed and simulated fields, a double application of common PC analysis has been introduced, first in space, then in time. The model performances are assessed from a misfit, a measure of the model-observation differences weighted by the data uncertainties. As the misfit depends on both the model performances and the quality of the oceanic and atmospheric data, the model testing procedure is best suited at detecting 

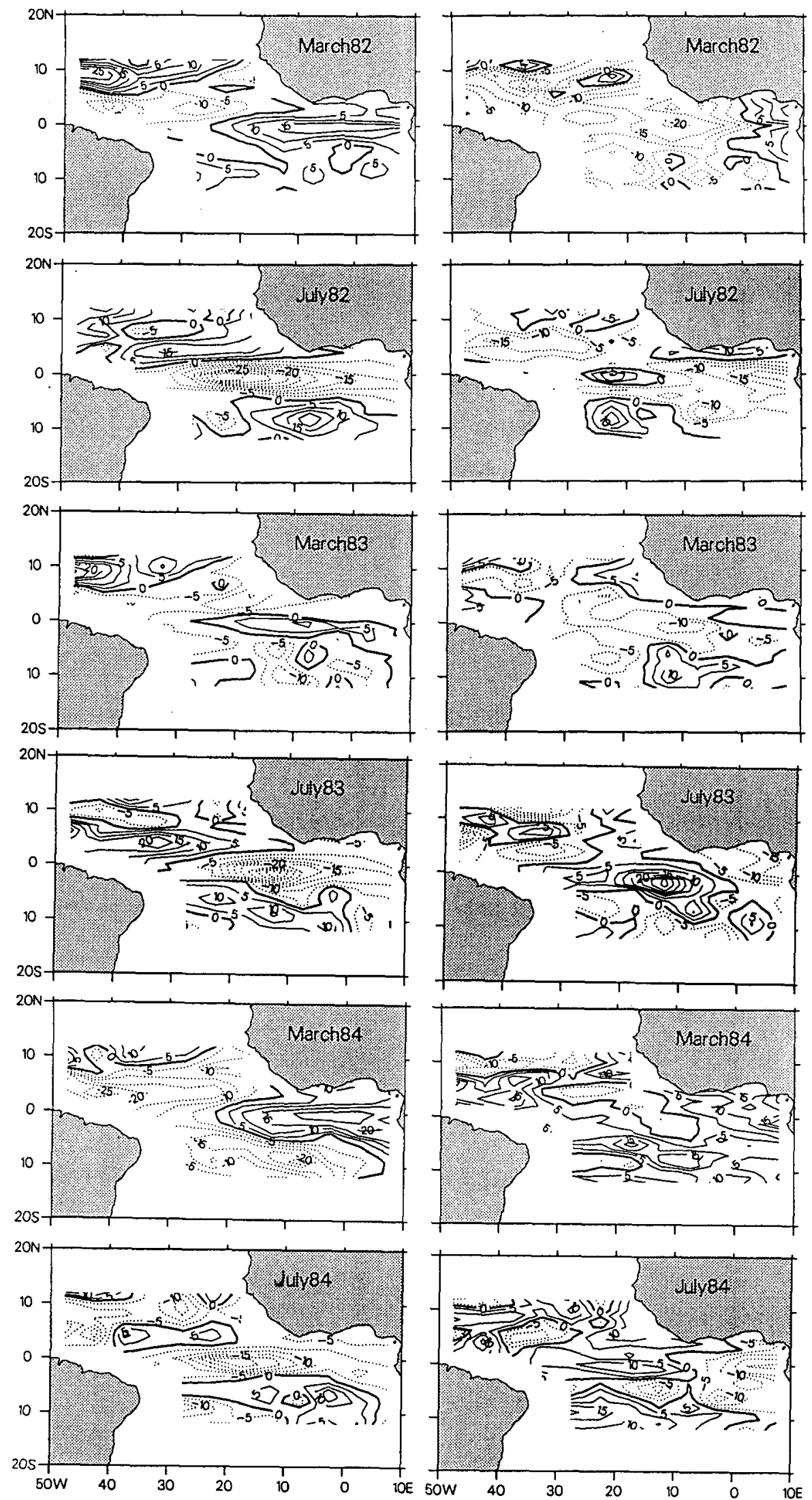

FIG. 15. As in Fig. 10 (middle and right) but for the LODYC GCM. 
TABLE 3. As in Table 1 but for the LODYC GCM.

\begin{tabular}{lccccc}
\hline $\begin{array}{c}\mathrm{CPC1} \\
(\%)\end{array}$ & $\begin{array}{c}\mathrm{CPC} 2 \\
(\%)\end{array}$ & $\begin{array}{c}\mathrm{CPC3} \\
(\%)\end{array}$ & $\begin{array}{c}\mathrm{CPC4} \\
(\%)\end{array}$ & $\begin{array}{c}\text { Total } \\
(\%)\end{array}$ \\
\hline $\mathbf{d}$ & 40.7 & 25.7 & 6.3 & 5.6 & 78 \\
$\hat{\mathbf{m}}$ & 37.8 & 23.5 & 10.1 & 5.1 & 76 \\
\hline
\end{tabular}

model deficiencies when using a highly accurate dataset; it is then a convenient tool for model tuning and intercomparison. Conversely, the method can be used to compare the quality of various datasets and their use for model improvement.

The model testing procedure has been applied to investigate the ability of Cane's (1984) linear multimode model at simulating the evolution of the $20^{\circ} \mathrm{C}$ isotherm depth in the equatorial Atlantic during the FOCAL/SEQUAL experiment, from January 1982 to December 1984. Particular care was devoted to representing the uncertainties in the atmospheric forcing and the oceanic initial conditions: using Monte Carlo techniques and five different drag laws, 25 equally plausible wind stress fields were constructed, consistently with the sample means and variances of the original ship measurements. The drag coefficient indeterminacy is thus better represented than in Frankignoul et al. (1989) and Leetmaa and Ji (1989), who, by simply varying the magnitude of a specific drag law, neglected the space-time modulations that may be linked to between-law differences in stability and speed dependence. Even though the FOCAL/SEQUAL years were particularly well sampled, the forcing errors were found to be large, often causing model response uncertainties as large as the interannual variability. The largest source of error is the drag coefficient indeterminacy, except in poorly sampled areas where sampling and measurement errors are comparable and even dominant. Note that in oceans with poorer data coverage like the tropical Pacific, sampling and interpolation errors would be much larger, leading to even larger forcing uncertainties. It was also shown that the stability dependence in the bulk formulas should not be neglected.

Although the linear model is able to successfully represent the main features of the thermocline depth variability observed during 1982-84, there are large differences with the observations that cannot be explained by the oceanic and atmospheric data uncertainties, and must therefore be attributed to the oversimplification of the model physics. In particular, the representation of the vertical displacements associated with equatorial upwelling is not realistic, and the model fails to properly represent the eastward progression of the thermocline shoaling that is observed in the Gulf of Guinea during summer. This certainly contributes to the difficulties encountered with the thermodynam- ical version of the model in simulating the summer cooling of sea surface temperature in this region (see Fig. 10 in Blumenthal and Cane 1989). Also, the linear model was found to generally underestimate the interannual variability of the thermocline depth. The model performances in a broad tropical region $\left(12^{\circ} \mathrm{N}-12^{\circ} \mathrm{S}\right)$ were compared to those in the equatorial waveguide $\left(3^{\circ} \mathrm{N}-3^{\circ} \mathrm{S}\right)$, but no significant difference could be detected; on the other hand, the superiority of the threevertical-mode version over the two-vertical-mode one was clearly established. These results primarily confirm Duchêne and Frankignoul's (1991) analysis of the mean seasonal variability of surface topography in the tropical Atlantic. Furthermore, it was shown that the FOCAL/SEQUAL data, with their substantial interannual variability, are a more accurate dataset for model testing and tuning than the dynamic height climatology extracted from the historical data files.

Although the linear model has now undergone substantial testing, it may seem disappointing that it is still difficult to determine exactly what is wrong with the model, besides its inadequate representation of upwelling. By considering model performances in the whole domain where it is valid and enough observations are available, and working in common EOF space, we have increased our ability at detecting model errors and intercomparing models, yet we have gained little for understanding which physical processes are misrepresented. However, more insight into the physics could be provided by using the model testing procedure in smaller regions with different dynamics (Braconnot 1992) and by generalizing the method to simultaneously tune a model and evaluate its sensibility to parameter changes (Scoffier et al. 1993).

A preliminary investigation of the performances of the LODYC GCM was also conducted. As only one simulation was available, the forcing uncertainties could not be considered, and only an upper bound of the GCM performances was obtained. Nonetheless, it was demonstrated that the GCM performed significantly better than the linear model both in the $12^{\circ} \mathrm{N}-$ $12^{\circ} \mathrm{S}$ region and in the equatorial waveguide. To properly simulate the effects of the forcing and initial conditions uncertainties, several GCM runs should be made. However, it is not realistic to require as many experiments with costly models as in the present study, nor is it really needed. A sensitivity study with the linear model shows indeed that, with only three to five wind stress fields differing both in drag formulation and pseudostress uncertainties, the test results remained unchanged (Braconnot 1992). A more complete validation study of the LODYC GCM using the FOCAL/ SEQUAL dataset has thus been undertaken, and the influence of various parameterizations tested. This will be reported soon, as well as an extension of our approach to the more complex problem of testing sea surface temperature simulations. 

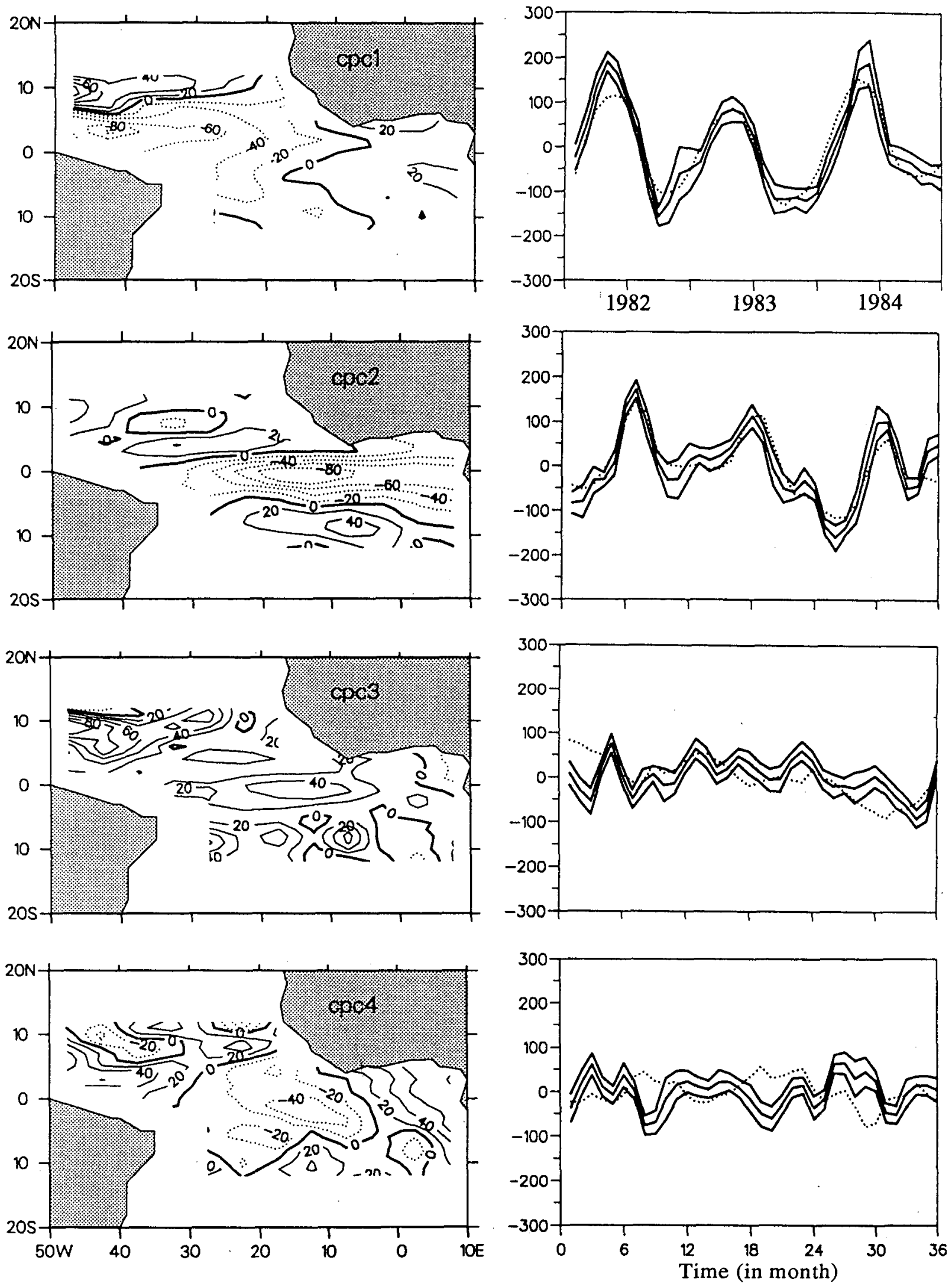

FIG. 16. As in Fig. 11 but for the LODYC GCM. 
Acknowledgments. We would like to thank Gilles Reverdin for providing his analysis of the FOCAL/ SEQUAL data, Alain Morlière for making available the GCM simulation, and the two of them for stimulating discussions. Thanks are also due to Christine Duchêne for her useful advice at the beginning of this study and to Benno Blumenthal for his help with the linear model. This research was supported by a grant from the PNEDC and by Contracts EV4C006 and EPOC-0003-C with the Commission of the European Communities.

\section{REFERENCES}

Blanc, T. V., 1985: Variation of bulk-derived surface flux, stability, and roughness results due to the use of different transfer coefficient schemes. J. Phys. Oceanogr., 15, 650-669.

- 1987: Accuracy of bulk-method-determined flux, stability, and sea surface roughness. J. Geophys. Res., 92, 3867-3876.

Blumenthal, M. B., and M. A. Cane, 1989: Accounting for parameter uncertainties in model verification: An illustration with tropical sea surface temperature. J. Phys. Oceanogr., 19, 815-830.

Blanke, B., and P. Delecluse, 1993: Low frequency variability of the tropical Atlantic ocean simulated by a general circulation model with mixed layer physics. J. Phys. Oceanogr., 23, in press.

Braconnot, P., 1992: Validation objective de modèles d'ocean tropical à l'aide des données FOCAL/SEQUAL. Thèse de doctorat. Université Pierre et Marie Curie, Paris, $144 \mathrm{pp}$.

Cane, M. A., 1984: Modeling sea level during El Niño. J. Phys. Oceanogr., 14, 1864-1874.

Cardone, V. J., J. G. Greenwood, and M. A. Cane, 1990: On trends in historical marine wind data. J. Climate., 3, 113-127.

Carton, J. A., and E. C. Hackert, 1989: Application of multi-variate statistical objective analysis to the circulation in the tropical Atlantic ocean. Dyn. Atmos. Oceans, 13, 491-515.

Duchêne, C., 1989: Test statistique de la validité des modèles océaniques équatoriaux à l'aide d'observations. Thèse de doctorat. Universite Pierre et Marie Curie, Paris, 166 pp.

driven tropical ocean models. J. Mar. Syst., 1, 97-117.

$\longrightarrow$, and -1991 : Seasonal variations of surface dynamic topography in the tropical Atlantic: Observational uncertainties and model testing. J. Mar. Res., 49, 223-247.

Du Penhoat, Y., and Y. Gouriou, 1987: Hindcasts of equatorial sea surface dynamic height in the equatorial Atlantic in 1982-1984. J. Geophys. Res., 92, 3729-3740.

Flury, B. N., 1989: Common Principal Components and Related Multivariate Models. Wiley and Sons, $258 \mathrm{pp}$.

Frankignoul, C., 1991: Oceanic model testing. Proc., Aha Huliko'a, Hawaiian Winter Workshop, Honolulu, Hawaii; P. Müller and D. Henderson, Ed., 387-397.

- C. Duchêne, and M. Cane, 1989: A statistical approach to testing equatorial ocean models with observed data. J. Phys. Oceanogr., 19, 1191-1208.

Harrison, D. E., 1984: Ocean surface wind stress. Large-Scale Oceanographic Experiments and Satellites, C. Gautier and M. Fieux, Eds., 99-115.

- W. S. Kessler, and B. S. Giese, 1989: Ocean circulation model hindcasts of the 1982-83 El Nino: Thermal variability along the ship of opportunity tracks. J. Phys. Oceanogr., 19, 397-418.
Houghton, R. Wo, 1989: Influence of local and remote wind forcing in the Gulf of Guinea. J. Geophys. Res., 94, 4816-4828.

Katz, E. J., 1987: Seasonal response of the sea surface to the wind in the equatorial Atlantic. J. Geophys. Res., 92, 1885-1893.

Kondo, J., 1975: Air-sea bulk transfer coefficients in diabatic conditions. Bound-Layer Meteor., 9, 91-112.

Landsteiner, M. C., M. J. McPhaden, and J. Picaut, 1990: On the sensitivity of Sverdrup transport estimates to the specification of wind stress forcing in the tropical Pacific. J. Geophys. Res., 95, 1681-1691.

Large, W. G., and S. Pond, 1981: Open ocean momentum flux measurements in moderate to strong winds. J. Phys. Oceanogr., 11 , 324-336.

Leetmaa, A., and M. Ji, 1989: Operational hindcasting of the tropical Pacific. Dyn. Atmos. Oceans, 13, 465-490.

Levitus, S., 1982: Climatological atlas of the world ocean. NOAA Prof. Paper, 13, U.S. Govt. Printing Office, Washington, D.C., $173 \mathrm{pp}$.

Liu, W. T., K. B. Katsaros, and J. A. Businger, 1979: Bulk parameterization of air-sea exchanges of heat and water vapor including the molecular constraints at the interface. Atmos. Sci., 36, 17221735.

Luther, D. S., and D. E. Harrison, 1984: Observing long period fluctuations of surface winds in the tropical Pacific: Initial results from island data. Mon. Wea. Rev., 112, 285-302.

McPhaden, M. J., A. J. Busalacchi, J. Picaut, and G. Raymond, 1988: A model study of potential sampling errors due to data scatter around bathythermograph transects in the tropical pacific. J. Geophys. Res., 93, 8119-8130.

Pacanowski, R., and S. G. H. Philander, 1981: Parameterization of vertical mixing in numerical models of tropical oceans. J. Phys. Oceanogr., 目1, 1443-1451.

Philander, S. G. H., 1986: Unusual conditions in the tropical Atlantic ocean in 1984. Nature, 322, 136-238.

Reverdin, G., P. Delecluse, C. Levi, A. Morlière, and J. M. Verstraete, 1991: The near surface tropical Atlantic in 1982-1984. Results from a numerical simulation and data analysis. Progress in Oceanography, Vol. 27, Pergamon, 273-340.

Scoffier, N., C. Frankignoul, and M. A. Cane, 1993: An adaptive procedure for tuning a sea surface temperature model. J. Phys. Oceanogr., 23, in press.

Seber, G. A. F., 1984: Multivariate Observations. Wiley and Sons, $686 \mathrm{pp}$.

Servain, J., J. Picaut, and A. J. Busalacchi, 1985: Interannual and seasonal variability of the tropical Atlantic ocean depicted by 16 years of sea surface temperature and wind stress. Coupled Ocean-Atmosphere Models, J. C. J. Nihoul, Ed., Elsevier, 211237.

Smith, S. D., 1988: Coefficient for sea surface wind stress, heat fluxes and wind profiles as a function of wind speed and temperature. J. Geophys. Res., 93, 15 467-15 472.

Weisberg, R. H., 1984: Seasonal adjustments in the equatorial Atlantic during 1983 as seen by surface moorings. Geophys. Res. Lett., 11, 733-736.

- and T. Y. Tang, 1990: A linear analysis of equatorial Atlantic ocean thermocline variability. J. Phys. Oceanogr., 20, $1813-$ 1825 .

Wu, J., 1986: Stability parameters and wind stress coefficient under various atmospheric conditions. J. Atmos. Oceanic Technol., 3 , 333-339.

Yao, Y., 1965: An approximate degrees of freedom solution to the multivariate Behrens-Fisher problem. Biometrika, 52, 139-147.

Zebiak, S. E., and M. A. Cane, 1987: A model El Niño-Southern Oscillation. Mon. Wea. Rev., 10, 2262-2278. 